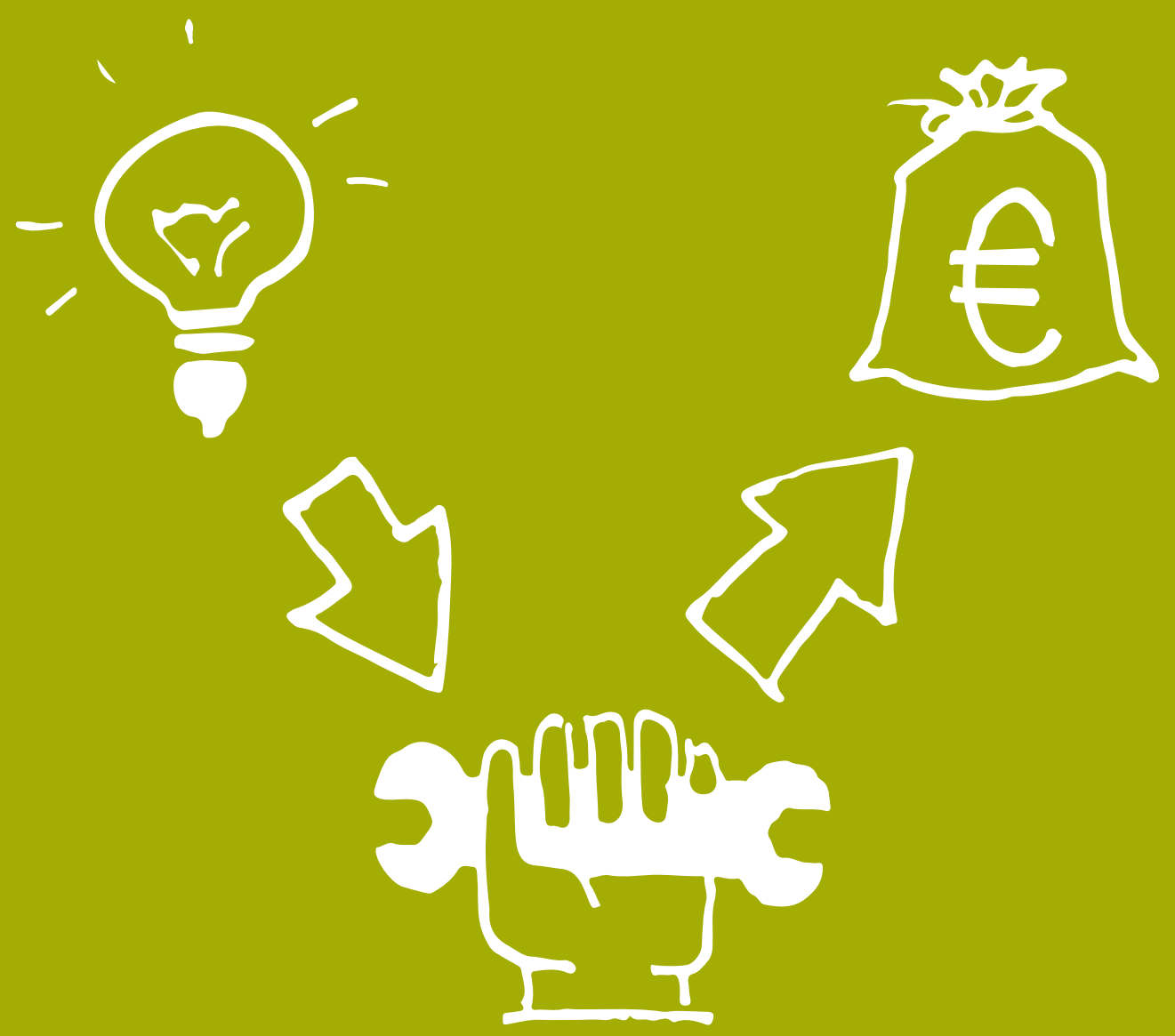




\section{3c empresa. Investigación y pensamiento crítico.}

Periodicidad trimestral. Quarterly periodicity.

Edición 35. Volumen 7, Número 3 (Agosto - noviembre '18). Edition 35, Volume 7, Issue 3 (August -

November'18).

Tirada nacional e internacional. National and internacional circulation.

Artículos revisados por el método de evaluación de pares de doble ciego. Articles reviewed by the double blind peer evaluation method.

ISSN: 2254-3376

$\mathrm{N}^{\circ}$ de Depósito Legal: A $268-2012$

DOI: http://dx.doi.org/10.17993/3cemp.2018.070335

Edita:

Área de Innovación y Desarrollo, S.L.

C/ Els Alzamora 17, Alcoy, Alicante (España)

Tel: 965030572

info@3ciencias.com _www.3ciencias.com

Todos los derechos reservados. Se autoriza la reproducción total o parcial de los artículos citando l a fuente y el autor. This publication may be reproduced by mentioning the source and the authors.

Copyright (C) Área de Innovación y Desarrollo, S.L.

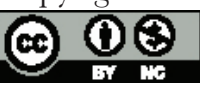


(3) empresa 


\section{Objetivo editorial}

La Editorial científica 3Ciencias pretende transmitir a la sociedad ideas y proyectos innovadores, plasmados, o bien en artículos originales sometidos a revisión por expertos, o bien en los libros publicados con la más alta calidad científica y técnica.

\section{Nuestro público}

- Personal investigador.

- Doctorandos.

- Profesores de universidad.

- Oficinas de transferencia de resultados de investigación (OTRI).

- Empresas que desarrollan labor investigadora y quieran publicar alguno de sus estudios.

\section{Cobertura temática}

La Revista 3C Empresa es una revista de carácter científico-social donde se difunden trabajos originales de investigación que abarcan diferentes temáticas relacionadas con las ciencias sociales, entre las que destacan la economía, la gestión empresarial e institucional y el ámbito educacional.

\section{Información para autores}

Toda la información sobre el envío de originales se puede encontrar en el siguiente enlace: http://www.3ciencias.com/normas-de-publicacion/instrucciones-para-el-envio-de-articulos/ 


\section{Publishing goal}

3Ciencias wants to transmit to society innovative projects and ideas. This goal is reached thought the publication of original articles which are subdue to peer review or thorough the publication of scientific books.

\section{Our target}

- Research staff.

- PhD students.

- Professors.

- Research Results Transfer Office.

- Companies that develop research and want to publish some of their works.

\section{Tematic coverage}

3c Empresa journal is a scientific-social journal, where original works are disseminated. These works cover different themes related to social sciences, such as economy, business and educational management.

\section{Instructions for authors}

All information about sending originals can be found at the following link: https://www.3ciencias.com/en/regulations/instructions/ 


\section{Indizado por}

Plataforma de evaluación de revistas
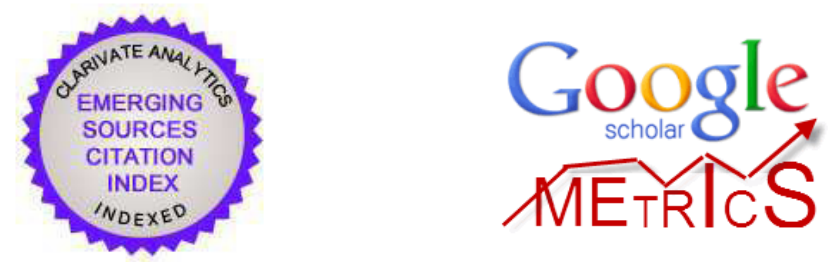

\section{MIAR \\ Matriu d'Informació \\ per a l'Avaluació de Revistes}

Bases de datos internacionales selectivas

\section{EBSCOhost}

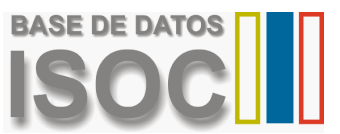

Business Source

Premier
答CSIC

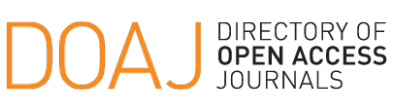

Business

\# Source Elite

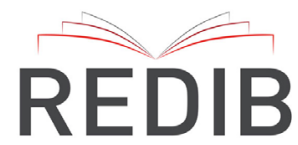

Red Iberoamericana

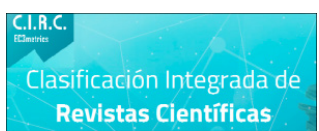

OAJl Open Academic 
Directorios selectivos

\section{latindex}

Hemerotecas selectivas

\section{O Dialnet}

Buscadores de literatura científica en acceso abierto 


\section{/SUMARIO/}


Elaboración de un sistema de acciones para la motivación en el desempeño laboral del personal docente, administrativo y de servicio de la Universidad Católica de Guenca, Extension Cañar

Elaboración de un sistema de acciones para la motivación en el desempeño laboral del personal docente, administrativo y de servicio de la Universidad Católica de Cuenca, Extension Cañar

Mariory-Prisila Orbe-Guaraca y Cristina-Guadalupe Ordoñez-Espinoza

Perspectivas de la economía digital en Latinoamérica: caso Ecuador

Perspectives of the digital economy in Latin America: case of Ecuador

Marjorie Marcela Acosta Véliz, Alfredo Yagual Velastegui y Verónica Coronel Pérez

Contribuciones económicas ancestrales sustentadas en la caña guadua en Jipijapa Manabí - Ecuador

Economic contributions customs basic in the bamboo cane of Fipijapa-Manabi - Ecuador

Robards-Javier Lima-Pisco, Alberto Rodríguez Rodríguez, Miguel Ángel Padilla Orlando y Adis Anicia Luna Báez

La gestión de procesos esbeltos como principio de mejora. Un caso aplicado a una comercializadora

Lean processes management as a principle of improvement. A case applied to a commerce

Blanca Carballo-Mendívil, Alejandro Arellano-González y Nidia Josefina Ríos-Vázquez

El fracaso del dinero electrónico en Ecuador

The failure of electronic money in Ecuador

John Alexander Campuzano Vásquez, Gonzalo Junior Chávez Cruz y José Maza Iñiguez 
/01/ 


\section{ELABORACIÓNDEUN SISTEMADEACCIONES PARA}

LA MOTIVACIÓN EN EL DESEMPEÑO LABORAL DEL PERSONAL DOCENTE, ADMINISTRATIVO $Y$ DE SERVICIO DE LA UNIVERSIDAD CATÓLICA DE CUENCA, EXTENSION CAÑAR

\section{ELABORATION OF A SYSTEM OF ACTIONS FOR MOTIVATION IN THE LABOR PERFORMANCE OF THE TEACHING, ADMINISTRATIVE AND SERVICE PERSONNEL OF THE CATHOLIC UNIVERSITY OF CUENCA, HEADQUARTERS CAÑAR}

Mariory-Prisila Orbe-Guaraca
Docente de la Universidad Católica de Cuenca, Extensión Cañar (Ecuador), Magister en Gestión
Empresarial.
E-mail: mporbeg@ucacue.edu.ec ORCID: https://orcid.org/0000-0002-4239-5675

Gristina-Guadalupe Ordoñez-Espinoza

Docente de la Universidad Católica de Cuenca, Extensión Cañar (Ecuador), Magister en Gestión Empresarial. E-mail: cgordoneze@ucacue.edu.ec ORCID: https://orcid.org/0000-0001-5781-7781

Recepción: 28/12/2018. Aceptación: 01/06/2018. Publicación: 24/08/2018

Gitación sugerida:

Orbe-Guaraca, M.-P. y Ordoñez-Espinoza, G.-G. (2018). Elaboración de un sistema de acciones para la motivación en el desempeño laboral del personal docente, administrativo y de servicio de la Universidad Católica de Cuenca, Extension Cañar 3C Empresa: Investigación y pensamiento crítico, 7(3), 10-27. DOI: http:// dx.doi.org/10.177993/3cemp.2018.070335.10-27/ 


\section{RESUMEN}

El presente trabajo plantea la elaboración de un sistema de acciones para el desempeño laboral de los empleados de la Universidad Católica de Cuenca, en concreto en la Extensión Cañar. Se ha realizado un diagnóstico para determinar el nivel motivacional de los empleados. La investigación fue un estudio de carácter descriptivo, bajo la modalidad de proyecto factible. A partir de ello se fijó la metodología, aplicándose encuestas y observaciones que facilitaron la elaboración de la propuesta. Se concluye así que el sistema de acciones potenciará que la instancia superior apoye a los empleados en cuanto a horario laboral, que se tomen en cuenta sus opiniones, la remuneración en tiempo y forma, capacitación continua, reconocimientos a la labor desempeñada, entre otros.

\section{ABSTRACT}

The present work pose to elaborate a system of actions for the labor performance of the employees of the Catholic University of Cuenca, specifically, in Extension Cañar. For its development it was necessary to make a diagnosis to determine the motivational level of the employees. The research was located in a descriptive study, under the feasible project modality. Based on this, the methodology was established, applying surveys and observations that facilitated the development of the proposed. It is concluded that the system of actions will empower the higher instance to support employees in terms of working hours, that their opinions are taken into account, remuneration in time and form, continuous training, recognition of the work performed, among others.

\section{PALABRAS CLAVE}

Sistema, Motivación, Desempeño, Laboral, Empleados.

\section{KEY WORDS}

System, Motivation, Performance, Labor, Employees. 


\section{INTRODUCCIÓN}

Uno de los propósitos de las organizaciones para ser exitosas y competitivas dentro del mercado donde se desempeñan es el aprovechamiento de la máxima capacidad laboral de sus empleados (alto rendimiento laboral), entre tanto la motivación de sus trabajadores debe ser uno de los aspectos de mayor atención para la operacionalidad de una actividad productiva. De ello depende la actitud laboral y la gran capacidad de asegurar la productividad con eficiencia y calidad.

En términos generales, se puede entender que la motivación es la fuerza que produce en el individuo la acción colaborativa y participativa. En virtud de ello, se debe considerar lo relevante de tomar en cuenta algunos aspectos que influyen como incentivo en la actitud proactiva de los trabajadores.

La realidad observada entre los empleados de la Universidad Católica de Cuenca, Extensión Cañar permitió conocer que gran parte de ellos están desmotivados, lo que resulta una preocupación respecto a la calidad en el trabajo a ejecutar.

En relación a lo antes expuesto, surge la necesidad de realizar una investigación, que ha procurado proponer un sistema de líneas de acciones para fomentar la motivación mediante estrategias que generen a los trabajadores una mejor actitud laboral y la disposición de desempeñarse para generar mayores niveles de productividad y eficiencia.

\section{LA MOTIVACIÓN}

Lévy Leboyer (2001), refiere que la motivación "es un concepto muy multidimensional, ya que apela a las nociones de dirección (el objetivo), de intensidad (el grado de esfuerzo) y de duración (la continuidad del esfuerzo)". Por ello, al hablar de un empleado motivado, debemos necesariamente hablar de un empleado que cumplirá sus funciones con calidad, prestando a su vez un servicio de excelencia a todos los usuarios y usuarias, aumentando la calidad en la prestación de servicios, y demostrando de esta manera la responsabilidad en su trabajo.

Para Manville (2004), el principal activo de una Empresa moderna no está formado por los edificios, la maquinaria y los bienes inmuebles que posee, sino por la inteligencia, la comprensión, las habilidades y la experiencia de sus empleados". Por lo tanto, un empleado motivado es un factor determinante para el logro de las metas de la empresa y los niveles de excelencia que desee alcanzar. Es decir, que el desarrollo y adelanto de una empresa o institución no está específicamente en lo material que tenga la misma, sino más bien se encuentra localizada en sus empleados, en la capacidad de desarrollar sus actividades y la eficiencia con la que lo realizan. 


\subsection{TEORÍAS DE LA MOTIVACIÓN}

Según Abraham Maslow, (citado por Gray, 2012) se concibe que conforme se satisfacen las necesidades más básicas, los seres humanos desarrollan necesidades y deseos más elevados, conllevándolos a mantenerse en un estado de motivación satisfactorio.

Según Clayton Alderfer, en la teoría ERG (citado por Robbins, 2004) manifiesta que existen tres grupos de necesidades básicas: existencia, relación y crecimiento.

Necesidades de existencia.- remite a la provisión de nuestros elementales requisitos materiales de subsistencia.

Necesidades de relación.- El deseo que tenemos de tener vínculos personales importantes. Estos deseos sociales y de status exigen, para satisfacerse, el trato con los demás y corresponden tanto a la necesidad social de Maslow como al componente externo de la necesidad de estima.

Necesidades de crecimiento.- El anhelo interior de desarrollo personal, aquí se incluye el componente interior de la categoría de estima de Maslow y las características propias de la autorrealización. De acuerdo a lo expresado es importante recalcar que las necesidades son factores importantes dentro de la motivación, ya que el ser humano realiza sus actividades esperando siempre contar con acciones que puedan ayudar a desempeñar su trabajo con eficiencia.

\subsection{MOTIVACIÓN LABORAL}

La motivación humana se define como un estado emocional que se genera en una persona como consecuencia de la influencia que ejercen determinados motivos (Koenes, 1996). Según lo anteriormente expuesto, los empleados deben estar debidamente motivados, de tal manera que podamos ejercer en ellos un estado emocional elevado y de esta manera lograr un desarrollo efectivo en su desempeño laboral. Para Claude Lévy, (2001) la motivación laboral es, en efecto, un resorte importante de una competición que es mundial.

Es decir, se debe motivar adecuadamente a cada uno de los individuos que conforman la Institución, ya que ellos son considerados como el motor de gran importancia ante las competencias que se nos presentan en el mundo actual. 


\subsection{SATISFACCIÓN EN EL TRABAJO}

Es una actitud hacia el trabajo, la satisfacción es un objetivo propio de la organización, no solo está relacionada de manera negativa con el ausentismo y la rotación sino que también las organizaciones deben brindar a sus empleados labores desafiantes e intrínsecamente recompensables.

Según Amorós (2007), existen factores determinantes de la satisfacción en el trabajo y entre ellas se pueden encontrar:

- Trabajo mentalmente desafiante. Es decir, aquel trabajo que le exija al empleado la realización de un esfuerzo mental por realizarlo, será preferido por este, ya que podrá poner en práctica todas sus habilidades.

- Recompensas justas. Cuando un empleado percibe que en la organización en la que trabaja existen políticas de ascensos justas, y que además su sueldo es el justo por la labor que desempeña.

- Condiciones favorables de trabajo. Cuando los empleados trabajan en condiciones seguras y cómodas de trabajo, se sentirán más satisfechos.

- Colegas que brinden apoyo. Tener colegas amigables que brinden apoyo va a tener como consecuencia una mayor satisfacción del empleado.

- Compatibilidad entre personalidad y puesto. Al estar presente estos factores, se puede manifestar que un empleado estará siempre satisfecho con sus responsabilidades, y por ende hará que se sienta identificado con la empresa en la cual labora. Y son éstos factores los que se esperan que logren tener los empleados de las diferentes empresas o instituciones.

\subsection{DESEMPEÑO LABORAL}

Para la administración, el adecuado manejo de los recursos de una empresa y su funcionamiento es indispensable y fundamental el talento humano, por lo que es imprescindible que el mismo posea la capacitación necesaria para el ejercicio de su cargo, de esta forma, el personal pasa a ocupar un lugar privilegiado en la organización, convirtiéndose en un elemento estratégico clave del éxito, siendo esto la fuente de toda ventaja competitiva (Arias Galicia, 2000).

Ahora bien, el trabajador para lograr los objetivos y las metas que se propone alcanzar no actúa aisladamente, debe relacionarse con el resto de los individuos que integran su entorno organizacional, 
de tal manera de lograr su adaptación al medio en el que se desenvuelven. En este orden de ideas, las empresas pueden influir en la vida diaria del personal para su desempeño, así como la calidad y sistema de vida de un individuo, en sus valores y costumbres que le permiten satisfacer sus necesidades sociales, psicológicas, laborales y económicas.

\section{METODOLOGÍA}

El estudio se fundamenta en una investigación descriptiva, que busca analizar la incidencia de la motivación y desempeño laboral de los empleados de la Universidad Católica de Cuenca, Extensión Cañar.

Se pretende hacer una descripción sobre cómo se manifiesta este fenómeno, de manera particular y qué situaciones puede estar generando.

La investigación toma en cuenta los siguientes aspectos:

- Grado de control de las variables,

- La temporalidad o momentos de recolección de datos, y

- El contexto donde se recolectó la información.

Es una investigación no experimental "por no manipular variables, se observan los fenómenos como se dan en su contexto para después analizarlos. No hay condiciones o estímulos a los cuales se expongan los sujetos... no se construyen situaciones se observan las ya existente" (Cursio, 2002). Por tanto, los escenarios y los sujetos coexisten en la cotidianidad, haciendo accesible su observación en la realidad.

Otro de los aspectos estimados en el diseño está referido al contexto donde se recolectó la información, enmarcándose en un estudio de campo, por ser los tomados en las instalaciones de la Extensión Cañar sin alterar los escenarios, lo que permitió hacer descripciones e interpretaciones del fenómeno tratado mediante la técnica de la encuesta utilizando un listado de preguntas escritas que se entregaron a los empleados quienes, en forma anónima, las respondieron por escrito.

La población implicada en el estudio estuvo conformada por ochenta y cinco (85) empleados que laboran en la Extensión Cañar y una muestra de sesenta y tres (63) empleados que fueron escogidos por medio de un muestreo simple que representan el 75\% de la población existente. 
La investigación correspondió a la modalidad de Proyecto factible, ya que a través de la propuesta se brindó atención a los empleados para garantizarles un clima laboral más satisfactorio.

\section{RESULTADOS}

En esta sección se muestran los resultados obtenidos de la aplicación de las encuestas y entrevistas. La encuesta se estructuró en preguntas cerradas y se utilizó la escala de Likert como medición de las preguntas. La misma se aplicó a 51 docentes, 12 directivos y administrativos, y 3 personas de servicio.

El 62\% expresa que nunca han recibido charlas sobre motivación, lo que induce a la necesidad de tomar acciones en cuanto a las capacitaciones que se debe desarrollar para mejorar el desempeño de los empleados.

Responde el 71\% de los encuestados que nunca realizan programas de incentivos, lo que resulta un elemento muy negativo para la institución, el nivel de satisfacción en ese aspecto es insuficiente. La información adquirida ayudará a elevar la autoestima y motivación del empleado a través de los programas de incentivos.

El 38\% y el 27\% están de acuerdo a que la manera de fijar salarios en la institución es equitativa siendo este aspecto significativo para la motivación del personal que servirá para satisfacer las necesidades de los empleados y lograr de esta manera estabilidad laboral.

El hecho de que se realicen eventos sociales para motivar al personal es reconocido con las escalas de a veces, frecuentemente y siempre por el $85 \%$ de los participantes en la muestra, lo que se considera como un indicador positivo para la motivación en el desempeño del personal y a la vez reducir el nivel de estrés en los mismos.

El 47\% de los informantes coloca en el rango de nunca el hecho de que las ideas, pensamientos u opiniones expresadas por los docentes, no sean tomados en cuenta. No obstante, la información obtenida sobre este indicador permitirá tener en cuenta actividades participativas destinadas a recoger estados de opinión y propuestas de mejoramiento por parte del colectivo de la comunidad educativa.

El 41\% de los encuestados considera que a veces es razonable y justa la carga horaria que tienen. Sin embargo, cuando el 30\% y 21\% señalan que no han tenido cambio alguno en sus actividades, 
es decir, que se desempeña durante mucho tiempo en sus actividades rutinarias. Esta información permitirá que los superiores asignen tareas acordes al perfil de cada empleado y a la carga horaria establecida por el organismo superior.

El 49\% de los informantes consideran que nunca los directivos respaldan a sus empleados para asistir a eventos de capacitación, lo que resulta negativo. El resultado adquirido permitirá que los superiores incentiven y apoyen a sus empleados a ser partícipes de eventos de capacitación para la superación de su personal.

La labor desempeñada por un empleado debe ser reconocida, ya que es un elemento fundamental para fomentar la autoestima y la motivación en la institución. A partir de este indicador, también se fomenta la participación en las tareas de la institución. El hecho de que solamente el 29\% de los participantes en plantee que es reconocido el trabajo que desempeñan, presupone la existencia de falencias en la motivación de los mismos, lo que indica la necesidad de plantear acciones en función de esa dificultad.

El 39\% expresa que a veces el ambiente de trabajo en el sitio donde laboran es tenso, lo que resulta un elemento muy negativo para que el empleado pueda realizar sus actividades. Este resultado nos brinda la información necesaria para emplear cursos de relaciones interpersonales que permitan estrechar lazos de amistad entre los compañeros de tal modo que ayude a mejorar las relaciones.

La mayoría de la muestra está en la categoría siempre, con un 52\%, lo que resulta un elemento muy positivo, evidencia que existen más personas motivadas a trabajar en sus áreas que personal desmotivado. La información obtenida permitirá que las autoridades de la institución mantengan a sus empleados laborando en departamentos donde ellos se sienten cómodos a desarrollar sus actividades diarias.

La mayoría del personal docente, administrativo y de servicio en un 51\%, se siente a gusto con su equipo de trabajo, de modo que al analizar estos resultados se puede observar que en el personal existen valores como la solidaridad, el respeto, la amabilidad, el compañerismo, etc. Conocer esto ayudará a mantener los niveles de satisfacción de los empleados en los distintos departamentos.

Con una diferencia de 5\% entre las respuestas el sentido de seguridad brindada por la institución es satisfactorio, esto refleja que casi la mitad de la población se siente insegura en su puesto laboral. Es necesario que la Institución brinde seguridad a todo el personal independientemente de sus horas de labor y de las actividades que desempeñen y de esta manera buscar perfeccionar este indicador favorablemente. 
Es evidente que el estado de ánimo es un factor que si influye en las labores cotidianas pudiendo este causar dificultades al realizar sus actividades diarias puesto que el 74\% de la población así lo expresa. La información alcanzada nos permitirá realizar charlas que ayuden a concientizar a los empleados para que no manifiesten sus problemas personales en sus áreas de trabajo.

El $81 \%$ de los empleados consideran que la remuneración es un factor que incide de manera significativa en el trabajo. El resultado obtenido ayudará a mantener al personal motivado y a mejorar la calidad del desempeño en cada una de las áreas en las que se desenvuelven los empleados.

Las remuneraciones económicas, al ser una acción altamente motivante para un ser humano dentro del desarrollo de sus actividades deberían ser canceladas puntualmente, es necesario que las autoridades utilicen estrategias que permitan cancelar a tiempo los sueldos puesto el 84\% de ellos indican que no se cumple puntualmente. Es por ello que la información adquirida ayudará a que la administración realice las gestiones pertinentes para que los sueldos sean cancelados con puntualidad.

Los logros alcanzados por los empleados son elementos fundamentales que motivan al ser humano. Pero, solamente el $29 \%$ de los participantes en la muestra plantea que siempre o frecuentemente les refuerzan cuando obtienen un logro no es razón suficiente para manifestar que las autoridades no deban tomar acciones sobre este indicador.

Resulta un elemento muy negativo el hecho de que los superiores no adquieran actitudes positivas para manifestarse ante posibles dificultades que pueden presentarse en la institución un 36\% de la población encuestada cree esto.

\section{PROPUESTA}

Se definen seguidamente las fases que conforman el sistema de acciones motivacionales.

\subsection{FASE 1: Capacitación y Actualización del personal}

La propuesta se basa en la creación de diferentes cursos, charlas motivacionales, capacitaciones, cursos y talleres de actualización de conocimientos dirigidos a los empleados y docentes, los cuales serán seleccionados de acuerdo a sus necesidades. 
Para esta propuesta es necesario contar con la interacción de la Universidad Católica de Cuenca, Extensión Cañar por medio del Programa de Capacitación y Actualización Docente. Es de suma importancia indicar que los cursos de formación, capacitación y actualización deberán realizarse en un tiempo mínimo de tres meses para poder así cubrir todas y cada una de las necesidades descubiertas.

Una vez que se tenga en cuenta los objetivos y habiendo seleccionado los contenidos necesarios, se deben agrupar en módulos temáticos por cada una de las áreas que se requiere capacitarse. Se procederá a solicitar la estructuración de las capacitaciones seleccionadas a la Universidad Católica de Cuenca, Extensión Cañar a través del Programa de Capacitación y Actualización Docente para destacar las actividades a desarrollar y acciones seleccionadas para el logro de las mismas.

El programa de Formación y Actualización estará dirigido a:

1. Jefes: El jefe adoptará la formación y actualización necesaria, que le permita instruirse y sensibilizarse ya sea formativa o informativamente en temas de su área.

2. Docentes: Se les dará a conocer fundamentos teóricos y prácticos, todo esto con la finalidad de incrementar el rendimiento eficiente del personal, mediante el avance de sus habilidades y destrezas, creando un conocimiento formador y aumentando así un valor adicionado al personal de la institución.

3. Administrativo: Se capacitará a los mismos en temas relacionados con el área de relaciones humanas de tal modo que permita mejorar el desempeño laboral.

4. Personal de Servicio: Se capacitará en las áreas en las que ellos se desempeñan, con temas actuales para crear una conciencia formadora y responsable.

Acción: Se estimarán en acuerdo con la Universidad Católica de Cuenca, Extensión Cañar y el área de recursos humanos.

Tiempo de Ejecución: Trimestralmente.

Dirigido a: Superiores, Personal Docente, Administrativo y de Servicio de la UCACUE, Extensión Cañar. 


\subsection{FASE 2: Optimizar la comunicación entre los empleados y también de empleados a superiores}

Esta fase se llevará a cabo con la finalidad de tomar en cuenta todas las sugerencias y preguntas que los empleados deseen hacer o comunicar a sus superiores, de esta manera se les puedan dar las respectivas soluciones. Esta fase o etapa se efectuará en base a las siguientes acciones:

1. Colocar un buzón de sugerencias.

2. Reuniones en el lugar de trabajo dirigidas por los superiores.

3. Motivar a los empleados para que establezcan relaciones comunicativas.

\subsection{FASE 3: Programa de Incentivos para los empleados}

1. Incentivos a los trabajadores destacados en sus áreas de trabajo (el mejor empleado).

2. Eventos Sociales.

3. Flexibilidad horaria: Brindar al empleado distintas opciones de horarios y dejar que los empleados lo elijan.

4. Elección de días libres y vacaciones: esta medida facilitará la conciliación laboral y familiar de tus trabajadores.

5. Integración en la institución: Incrementar el sentimiento de pertenencia a la institución y así fomentar la productividad y la consecución de objetivos.

6. Recompensas al personal, por determinados objetivos claramente definidos: Es decir se puede recompensar a un empleado luego de un determinado tiempo de permanencia en la organización.

7. Remuneraciones: es importante gestionar la puntualidad de los pagos a los empleados tener en cuenta si los trabajadores tienen problemas tanto personales como de salud no afectar el salario que recibe el empleado.

8. Seguridad: informar a los empleados sobre los riesgos laborales a los que están expuestos, mantener en buen estado de servicio las instalaciones, máquinas, herramientas y materiales para un trabajo seguro. 
Organizar y facilitar los servicios médicos, comités, y departamentos de seguridad.

Entregar gratuitamente a sus trabajadores vestido adecuado para el trabajo y los medios de protección personal y colectiva necesarios.

Efectuar reconocimientos médicos periódicos de los trabajadores en actividades peligrosas; y, especialmente, cuando sufran dolencias o defectos físicos o se encuentren en estados o situaciones que no respondan a las exigencias psicofísicas de los respectivos puestos de trabajo.

\subsection{FASE 4: Desarrollar el interés y la participación individual o grupal}

Tiene como objetivo principal desarrollar el interés y la participación individual o grupal, a través de la creación de:

1. Concursos: Se realizan entre trabajadores a modo de poner su ingenio a prueba y que ellos demuestren, de una manera u otra que pueden realizar actividades semejantes a su trabajo, como los son carteleras informativas, concursos de nacimientos (navidad), concursos de cantos en fechas festivas entre otras. Se recomienda que estas actividades sean desarrolladas por departamentos.

2. Competencias: Se realizarían actividades como torneos deportivos, conformando equipos por los diferentes departamentos de la organización para las distintas disciplinas deportivas, que sean de gran atracción para los empleados.

\section{CONCLUSIONES}

La motivación laboral está sujeta a varios factores que influyen en el desempeño de los empleados de la Universidad Católica de Cuenca, Extensión Cañar, por lo que muestra que no existen programas de formación y capacitación que permitan mantener a sus empleados actualizados en sus áreas de conocimiento, así como también las instancias superiores no respaldan a sus empleados para ser partícipes de eventos de capacitación.

El sistema de acciones motiva el desempeño laboral del personal docente, administrativo y de servicio de la Universidad Católica de Cuenca, Extensión Cañar, responde a las necesidades motivacionales de los empleados. Se ajustan al logro de una mejor ocupación laboral, provee, además, oportunidades para que los empleados puedan sentirse motivados y desempeñar su labor de una forma más eficiente, además se respeten las opiniones de los empleados a la hora de tomar las 
decisiones, que la remuneración económica sea cancelada puntualmente. Por otra parte el sistema de acciones incluye que cuando los trabajadores obtengan logros sean reforzados adecuadamente por los superiores.

En base a los indicadores del desempeño laboral analizados se puede concluir que el sistema de acciones potenciará los mismos de manera que la instancia superior apoye a los empleados en cuanto al horario laboral, que se tomen en cuenta sus opiniones, la remuneración en tiempo y forma, capacitación continua, reconocimientos a la labor desempeñada, entre otros. 


\section{REFERENCIAS BIBLIOGRÁFICAS}

Amorós, E. (2007). Comportamiento Organizacional. En Busca del Desarrollo de Ventajas Competitivas. Lambayeque, Perú: Biblioteca Virtual EUMENET.

Ardilla, R. (2001). Psicología del Aprendizaje. Mexico D.F., México: Siglo XXI editores, S.A.

Arias, F. (2006). El proyecto de investigación. Introducción a la metodología científica. Caracas, Venezuela.

Bravo, J. (1998). Estrategias de Crecimiento. Madrid, España : Diaz de Santos.

Bittel, L. (2000). Administración de Personal. José Real Gutiérrez (trad.).

Carrión, J. (2007). Estrategias de la Visión a la Acción. Madrid, España: Editorial Esic.

Gifuentes, Y. (2012). Inclusión de Estrategias de Motivación en la unidad de bienestar social para el personal que labora en el hotel Venetur Puerto Cabello. Informe de pasantías administrativas. Colegio Universitario Hotel Escuela de los Andes Venezolanos. Mérida, Venezuela.

Glaude Lévy, L. (2001). La motivación en la empresa. España: Ediciones Gestión 2000.

Colom, A., Serramona, J. y Vázquez, G. (2004). Estrategias de formación en la empresa. Madrid, España: Narcea S.A.

Cursio, C. (2002). Investigación cuantitativa: una perspectiva epistemológica y metodológica. Colombia: kinesis.

Colegio Universitario Hotel Escuela de los Andes Venezolanos. (2012). Propuesta para la Implementación de un Programa de Motivación para los trabajadores del Hotel Venetur Maracaibo.

Chiang, M. (2010). Relaciones entre el clima organizacional y la satisfacción Laboral. Madrid, España: Servicios Editoriales.

Ghiavenato, I. (2009). Gestión del Talento Humano. México D.L., México: Mc Graw Hill.

Díaz Narváez, V. (2009). Metodología de la investigación científica. Santiago, Chile: RIL.

Dorneyei, Z. (2008). Estrategias para la motivación en el área de Lenguas. Barcelona, España: Editorial UOC.

Finol, M. y Camacho, H. (2006). El proceso de investigación científica. Maracaibo, Venezuela: Ediluz. 
Garrido, F. J. (2004). Las claves de la comunicacion empresarial en el siglo XXI.

Garrido Luque, A. (2006). Sociopsicología del trabajo. Barcelona, España: UOC.

Gray, B. (2012). Sociología de la empresa’ 09. Recuperado de: http://sociologiaempresa09.wordpress. com

Grisolia, M. (2011). Estrategias para el mejoramiento del clima organizacional en el Hotel Venetur Margarita. Informe de pasantías administrativas. Grado de Técnico Superior Universitario en Hotelería y Servicios de la Hospitalidad. Colegio Universitario Hotel Escuela de los Andes Venezolanos. Mérida, Venezuela.

Hernández R., Fernández C. y Baptista, P. (2006). Metodología de la investigación. México D.L., México: McGraw Hill.

Hurtado, J. (2008). Cómo formular objetivos de investigación. Caracas, Venezuela: Sypal.

Koenes, A. (1996). Gestión de la calidad total. Madrid, España: Díaz de Santos.

Léboyer, L. (2003). La motivación en la empresa. Modelos y Estrategias. Barcelona, España: Edición de gestión 2000.

López, G. (2001). Motivación con base en incentivos salariales. ¿Realmente funciona? Recuperado de: http:// www.gestiopolis.com/canales/derrhh/articulos/27/motivar.htm

Manville, B. (2004). La Motivación de Personas. Recuperado de: http:/ /books.google.co.ve

Morris, G. G. (2001). Introducción a la Psicología. MéxicoD.F., México:Prentice-Hall Hispanoamericana.

Nelson, B. (2005). 1001 Formas de motivar a los empleados. Bogotá, Colombia: Editorial Norma.

Palella, S. y Martins, F. (2004). Metodología de la Investigación Cuantitativa. Venezuela: FEDUPEL.

Palomo Vadillo, M. (2010). Liderazgo y motivación de equipos de trabajo. Madrid, España: ESIC.

Pérez, G. (2000). Elaboración de proyectos sociales. Casos prácticos. Madrid, España: Narcea.

Pinder. (2008). Motivación enfoque contemporáneo.

Piñango, 1. (2007). Introducción a la metodología Científica. Caracas, Venezuela. 
Quiros, P. y Cabestrero, R. (2008). Funciones Activadoras: principios básicos de la motivación y la emoción. Madrid, España: Editorial Universitaria Ramón Areces.

R. Wayne, M. (2005). Administración de Recursos Humanos. México D.F., México: PEARSON.

Reyes Ponce, A. (2004). Administración de Personal Sueldos y Salarios. México D.F., México: LIMUS, S.A.

Robbins, S. (1998). Comportamiento Organizacional. Mexico D.F., México: Prentice. 
Ed. 35. Vol.7 N N 3. Agosto-Noviembre 2018
Dol: httpp///dx.doi.org/10.17993/3cemp.2018.070335.10-27/

127 
/02/ 


\section{PERSPECTIVAS DE LA ECONOMÍA DIGITAL EN LATINOAMÉRICA: CASO ECUADOR \\ PERSPECTIVES OF THE DIGITAL ECONOMY IN LATIN AMERICA: CASE OF ECUADOR}

Marjorie Acosta

Docente en la Universidad de Guayaquil-Facultad de Ciencias Administrativas. Ingeniera Comercial, Magíster en Administración y Dirección de Empresas (Ecuador). E-mail: marjorie.acostavq@ug.edu.ec ORCID: http://orcid.org/0000-0002-9462-1881

Alfredo Yagual Velastegui

Docente en la Universidad de Guayaquil-Facultad de Ciencias Administrativas. Ingeniero en Gestión Empresarial Internacional, Contador Público Autorizado, Magister en Administración de Empresas

(Ecuador).

E-mail: alfredo.yagualv@ug.edu.ec ORCID: https://orcid.org/0000-0001-9156-9160

Verónica Coronel Pérez

Docente en la Universidad de Guayaquil-Facultad de Ciencias Administrativas. Economista, Magíster en Administración y Dirección de Empresas (Ecuador). E-mail: veronica.coronelpe@ug.edu.ec ORCID: https://orcid.org/0000-0001-9771-367X

Recepción: 03/01/2018. Aceptación: 25/05/2018. Publicación: 24/08/2018

Citación sugerida:

Acosta, M., Velastegui, A. Y. y Coronel Pérez, V. (2018). Perspectivas de la economía digital en Latinoamerica: Caso Ecuador. 3C Empresa: Investigación y pensamiento crítico, 7(3), 28-43. DOI: http://dx.doi. org/10.177993/3cemp.2018.070335.28-43/ 


\section{RESUMEN}

El presente artículo brinda una perspectiva general de los elementos que conforman una economía digital y las perspectivas que tienen los países latinoamericanos con respecto a su incursión, se analiza el caso de Ecuador a través de datos estadísticos recientes para determinar la brecha digital que debe cubrirse para lograr incorporar y consolidar la digitalización económica en todos sus ámbitos. Se evidencia así que Ecuador tiene mucho potencial para explorar principalmente en el ámbito de uso de internet, compras, ventas y medios de comunicación. En este sentido, la inversión es clave para que el uso de la tecnología llegue a todos los espacios de la sociedad en sus múltiples variantes y se tecnifique a la mano de obra y ciudadanía en general para potenciar su uso y fortalecer la economía digital en el Ecuador.

\section{ABSTRACT}

This article provides a general perspective of the elements that make up a digital economy and the perspectives that Latin American countries have regarding their incursion, the case of Ecuador is analyzed through recent statistical data to determine the digital divide that must be covered to achieve incorporate and consolidate the economic digitalization in all its areas. It is evident that Ecuador has a lot of potential to explore mainly in the field of internet use, purchases, sales and media. In this sense, investment is key so that the use of technology reaches all areas of society in its multiple variants and technifies the workforce and citizens in general to enhance its use and strengthen the digital economy in the Ecuador.

\section{PALABRAS CLAVE}

Economía digital, Brecha digital, Sociedad del conocimiento, TIC.

\section{KEY WORDS}

Digital economy, Digital divide, Knowledge Society, ITC. 


\section{INTRODUCCIÓN}

La globalización ha permitido que la información y comunicación fluyan en forma vertiginosa en los últimos años a través de los distintos medios de índole digital. La tecnología avanza, y con ella nuevas y mejores implementaciones al servicio del sector público como del sector privado cambiando la forma de hacer negocios, de gestionar el conocimiento, de emprender y desarrollar la presencia de las empresas e instituciones en el siglo XXI, de tal forma que "en la era de la tecnología se visualiza que el empleado debe estar familiarizado con el uso de herramientas necesarias que influyen en sus ámbitos laborales" (Jiménez, Acosta, y Salas, 2017, p. 64). Por tanto, es vital conocer los aspectos claves del ecosistema digital y como a través de ellos las organizaciones convergen en un estado de alta competitividad gracias al aprovechamiento de los recursos disponibles dentro de una red de naturaleza abierta. La globalización y la disrupción tecnológica han provocado una evolución en las empresas, generando ciudades inteligentes, potenciando acceso a educación, nuevos empleos, inclusión financiera, entre muchos otros beneficios de la economía digital que involucran todos los sectores de la sociedad.

Las revoluciones por las que ha atravesado la sociedad trajeron nuevas formas de organización, en un primer periodo pasó a la mecanización de sus procesos entre 1760 y 1830 (agua y vapor), el segundo período en 1850 permitió la producción en masa y apareció la electricidad, el tercer período está lleno de innovaciones de índole tecnológico, comunicación e información y ésta se logra finalizando el siglo XX. Schwab (2016), indica que aparece en escena un nuevo período que lleva a la sociedad a la automatización total de la producción denominándola Cuarta Revolución o Revolución 4.00, en la que se plantea que exista una total independencia de la mano de obra humana, estableciendo una fusión de tecnologías, transistores, internet, teléfonos inteligentes, computadoras personales, big data, internet de las cosas, inteligencia artificial, entre otros. De tal forma, las naciones principalmente latinoamericanas deben adaptarse para que se reflejen de forma óptima las habilidades y características de los participantes de estos nuevos mercados digitales y generar un marco regulatorio para su desempeño en la economía digital.

En este contexto, es inevitable que se generen brechas digitales que es necesario cubrir para que esta economía funcione de forma sistemática ya que para Guzmán, Muñoz, Álvarez y Velázquez (2014) en este proceso actúan la escuela, el gobierno y la empresa de conjuntamente para cubrir las brechas creando espacios de aprendizaje y facilitación de contenidos, así como la accesibilidad a equipos, esto contemplando un visión social, económica e incluyente que cubra a todos los participantes de la sociedad. 
De acuerdo a datos del BID (2017), en Latinoamérica aún no se aprovechan las tecnologías al máximo, apenas un 3.74\% en relación por ejemplo a Singapur que las aprovecha al 6,04\%, el internet apenas pueden usarlo el 49,41\% de los ciudadanos, y de acuerdo a estos resultados en el 2016 solo el 4.46\% explota el uso de estas tecnologías en las empresas. En la escala del 1 al 10 Latinoamérica se encuentra en el 50,90\% de avance hacia el desarrollo de gobiernos digitales. Estas estadísticas permiten observar que si bien muchas empresas adquieren tecnologías, no se están aplicando en su totalidad para mejorar los procesos productivos, de distribución, en robótica e inteligencia artificial, por tanto el presente análisis detallará las principales conceptualizaciones de la economía digital y las perspectivas de los países latinoamericanos como el Ecuador para hacer frente a los retos de la sociedad digital aprovechando sus oportunidades y desafíos.

\section{ECONOMÍA DIGITAL}

Esta economía se conceptualiza como el confluir de agentes de mercado fundamentados en tecnologías que permiten su interacción. No solo representan digitalizar sus canales de comunicación y comercialización, sino agregar valor a sus bienes o servicios procurando que el consumidor final sienta satisfechas sus necesidades de forma eficiente. Este proceso de transformación convierte a la empresa convencional en una industria 4.0 y, por tanto, en una empresa para la economía digital donde sus actores públicos y privados deben identificar roles y aportes dentro de estos nuevos contextos y como indica Mossberger, Tolbert y McNeal (2008), generando nuevos modelos de negocios como el comercio electrónico.

Lombardero (2015), señala que los cambios que conllevan el involucramiento en la economía digital acompañan a cambios en las empresas y en la gestión y esto vincula a las personas que son el centro de la transformación, por tanto, el éxito de la economía digital depende mucho de quienes son los responsables de generarla y comunicarla a nivel empresarial y provocar los cambios regulatorios que convergen en su aplicabilidad en cualquier país del mundo.

Borrego (2014), indicaba que el crecimiento de los nuevos modelos de negocio digitales y lo complejo de su comportamiento, obligan a tomar medidas que se ajusten a esta realidad y se deriven los ajustes necesarios para su correcto funcionamiento analizando su situación actual y futura y generando los cambios a los esquemas de empresa establecidos. 


\section{LA TRANSFORMACIÓN DIGITAL Y LA INDUSTRIA 4.0}

La economía digital, a través de la implementación de nuevas tecnologías, permite acceder a nuevos mercados, nuevas fuentes de generación de ingresos (innovaciones disruptivas) y mejorar el estado de las pequeñas y medianas empresas y su competitividad con apoyo de la digitalización. Es clave el papel del sector público, ya que permite la adopción de implementaciones que conlleven a la construcción de nuevas infraestructuras de conexión, regulaciones gubernamentales y el incentivo a la investigación y desarrollo de estos procesos.

La industria 4.0 está generando nuevos empleos vinculados al ambiente digital pero también disminuye otras por el grado de automatización al que se ha llegado con la tecnología. Por tanto, el talento humano debe estar preparado en tres habilidades básicas las genéricas, las especializadas y complementarias, siendo las primeras las que llevan al individuo a manejarse en ambientes de internet, la segunda es la habilidad para realizar programaciones y las complementarias que promuevan la interacción con robots e inteligencia artificial como lo indicaron Zhao, Wallis y Singh (2015).

Los países, de acuerdo a su vinculación con la digitalizacion tienen muchas formas de categorizarse, pero tres parámetros son esenciasles tal y como indica López (2016):

- Apertura de Datos

- Confianza Digital

- Emprendimiento Digital

Con estos parámetros, países como Colombia ocupan el segundo lugar en economía digital de Latinoamérica, siguiendo a Chile que ocupa el primer lugar, dando ejemplo a Latinoamérica de las grandes posibilidades que se tienen aprovechando la tecnología de forma eficiente, confiable y apoyando a los emprendimientos.

Los países de la región latinoamericana deben ser parte del desafío de la economía digital, la cual se convierte en un medio para lograr la inclusión social y económica de sus países como indica Buenadicha, Canigueral y De León (2017), siendo la tecnología un medio eficaz para ese objetivo. De ahí radica la importancia de su fortalecimiento en estos mercados y sus variantes disruptivas, Colombia y Chile son un ejemplo, el resto de naciones ya está incursionando en formación, alojamiento, transporte, serivicios profesionales, financiación colectiva, etc. todo a través de aplicaciones tecnológicas de vanguardia. 
Lamentablemente, otro desafío para latinomérica es la identidad digital que le permita a todos los ciudadanos ser parte de esta economía, ya que "1 de cada 10 ciudadanos no puede probar su identidad y, por lo tanto, no puede acceder a servicios básicos tales como educación, atención médica, beneficios sociales, acceso a capital u otro servicio" (Pareja, Pedak, Gómez, y Barros, 2017). Por tanto, es vital inversión y normativa jurídica que permita cubrir este nuevo reto latinoamericano.

\section{ECONOMÍA COLABORATIVA Y NUEVOS MODELOS DE NEGOCIOS}

Para Doménech (2015), esta expresión se usa para denominar en español a sharing economy, peer to peer economy, mesh o collaborative consumption y que constituyen la producción de nuevos bienes y servicios usando la tecnología informática para intercambiarlos. Aquí están inmersas grandes compañías como UBER, Cabify, Airnbnb, Amazon, Spotify y otras que han revolucionado el uso de internet a través de las transacciones online, permitiendo que este tipo de plataformas brinden a los usuarios la oportunidad de contactar a otros, publicando ofertas o demandando algún tipo de producto o servicio que satisfaga sus deseos y necesidades, existiendo un valor económico como intercambio de acuerdo a la capacidad del consumidor. Este tipo de empresas se mantiene en el mercado gracias al constante incentivo de mantener la calidad y que ésta sea difundida por sus usuarios.

$\mathrm{Al}$ implantarse estas formas disruptivas de innovación surgen también nuevos modelos de negocios basados en la confianza ya que como se afirma, la confianza es la moneda de la nueva Economía Colaborativa (Bostman, 2013). Se prevee de acuerdo a datos del (BID, 2017) que tiene una gran perspectiva de crecimiento y en 10 años aproximadamente pasaran al 50\% de los ingresos a nivel mundial y se fundamentan en actividades como venta de música, alquiler de habitaciones, transporte, préstamos, empleos on line, entre otras innovaciones.

Los actores de esta economía interactúan en todo el ciclo, como lo menciona Buenadicha, Canigueral y De León (2017) son las entidades con fin de lucro, las cooperativas o empresas sociales, las empresas sin fin de lucro, la comunidad y el sector gobierno, ya que éste emite las regulaciones haciendo que estos elementos fluyan de forma continua hacia la mejora de los bienes y servicios que en ella se intercambian y permiten a la comunidad transformarse digitalmente. 


\section{EL GOBIERNO Y SU PAPEL EN LA ECONOMÍA DIGITAL}

El papel del gobierno es vital para el éxito del desarrollo digital. De acuerdo a Porras (2017), para que el gobierno puede convertirse en un ente digital debe cumplir 5 pasos sinérgicos para lograr esta transformación exitosa como se visualiza en la Figura 1.

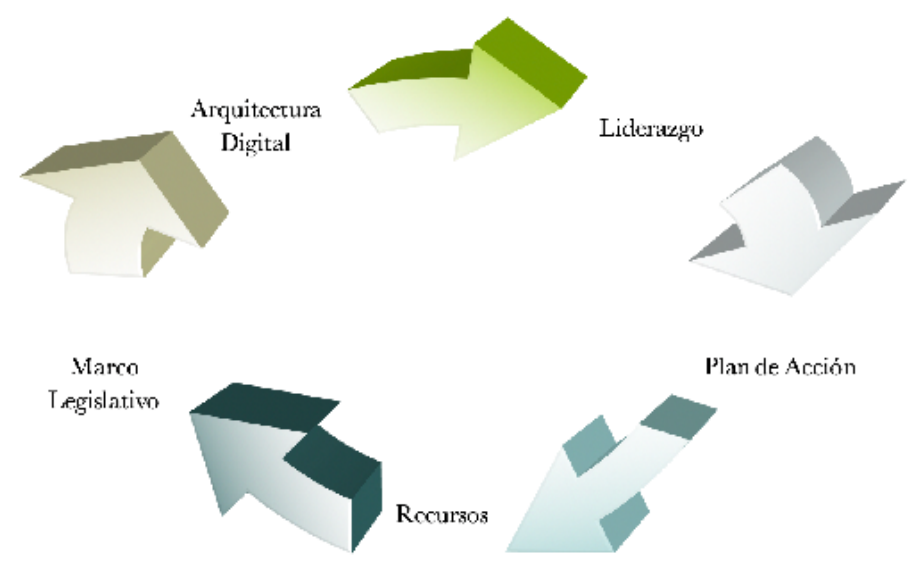

Figura 1. 5 pasos para que un gobierno se transforme en digital.

Fuente: elaboración propia.

Los gobiernos deben procurar que sus países se mantengan a la vanguardia y que las regulaciones no obstruyan las oportunidades de emprendimiento e inversión y más bien se vuelvan el apoyo para que estos negocios se consoliden, crezcan y se expandan a nuevos entornos. El gobierno debe tener información óptima sin sesgos, no debe dejarse influenciar por las empresas constituidas, debe ser ágil, mejorar sus tiempos de aprobación y adaptación a nuevas leyes, normas y reglamentos para proporcionar un entorno de calidad seguro.

La regulación de precios puede ser necesaria para promover una libre competencia y principalmente dar las mismas oportunidades, así el estado apoya de forma integral a estos nuevos modelos de negocios, como lo mencionan Kassan y Orsi (2012) se debe tener respuestas para estas nuevas actividades ya que muchas leyes están basados en realidades arcaicas y modelos obsoletos. 


\section{BLOCKCHAIN Y OTRAS INNOVACIONES}

Hoy en día se habla de Blockchain y unas de sus aplicaciones es conocida como las criptomonedas o el Bitcoin. El blockchain, de acuerdo a Hernández (2017), en esencia es un libro contable de transacciones que es controlado y monitoreado por varias fuentes de forma simultánea, siendo sus características ser distribuido, público, transparente, encriptado e inmutable. Esta disrupción tiene un gran potencial incluso de reemplazar a instituciones financieras. Entre sus aplicaciones potenciales están las microfinanzas, las remesas y pagos internacionales, registros digitales, seguimientos, contratos y las donaciones entre pares.

La visibilidad técnica, comercial y la deseabilidad humana confluyen de forma inseparable dentro de los entornos culturales, sociales económicos y hasta políticos para lograr el éxito de las innovaciones disruptivas que se generan en la sociedad del siglo XXI, la cual depara al mundo nuevos retos y por ello aparecen en escena tres grandes grupos de cambios que va a generar y ya está generado la nueva tecnología. GREYGROUP (2016), agrupó estos cambios de acuerdo a lo mostrado en la Figura 2.

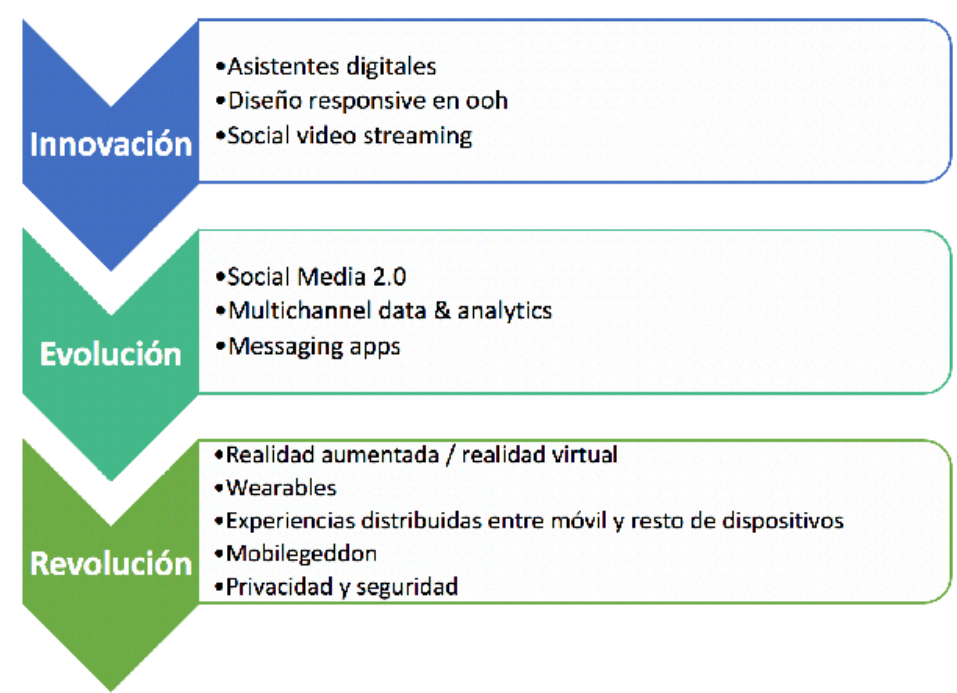

Figura 2. Nuevas Tendencias Digitales Adaptado de GREYGROUP (2016).

Fuente: elaboración propia. 
Las innovaciones no dejan de aparecer, evolucionan pero realmente el cambio se produce en la revolución, es decir en la disrupción, la que ha ganado nuevos clientes, la que ha mostrado nuevas maneras de hacer negocios y transformarlos haciéndolos más accesibles y de mayor calidad.

\section{ECUADOR Y SU BRECHA DIGITAL}

En el Ecuador, como parte de Latinoamérica, la brecha a cubrir es alta en los estratos públicos y privados. Se realizó una revisión de las principales estadísticas disponibles y determinar así algunas de las brechas que debe cubrir para llevar como éxito su incursión en la Economía Digital.

El INEC proporciona importante información que permite determinar la evolución y situación actual de la tecnología en los distintos ámbitos socioeconómicos, a continuación su principal monitoreo de acuerdo al INEG (2017).

En la Figura 3 se evidencia el aumento de computadores portátiles en los hogares que a lo largo de cinco años aumentó en 13,7 puntos y en el caso de las computadoras de escritorio se ha mantenido estable con una variación de 0,3 puntos.

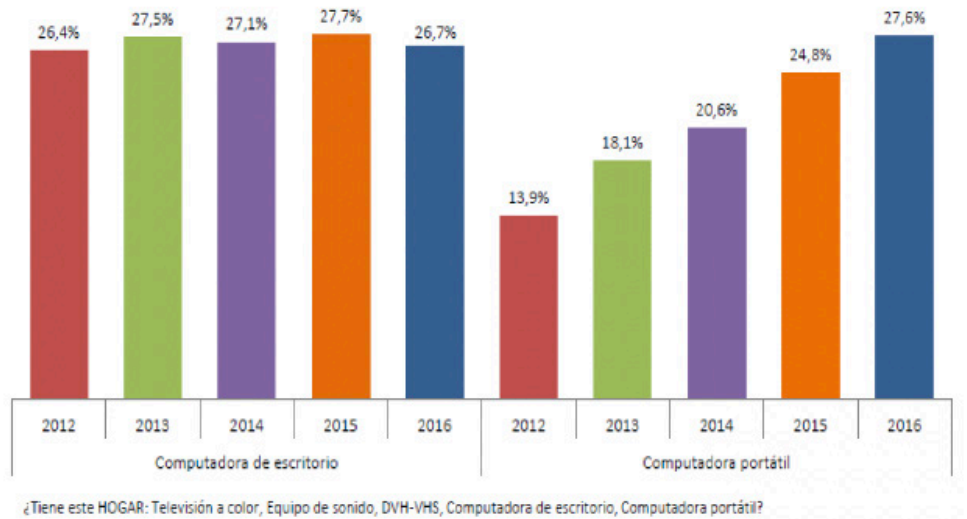

Figura 3. Equipamiento tecnológico del hogar a nivel nacional.

Fuente: Encuesta Nacional de Empleo Desempleo y Subempleo - ENEMDU (2012 - 2016).

La Figura 4 permite apreciar que el 36,0\% de los hogares tiene internet y el área urbana es la de mayor participación con un 44,6\%. El área rural tiene una menor participación pero su crecimiento ha sido de 11,6 puntos. 


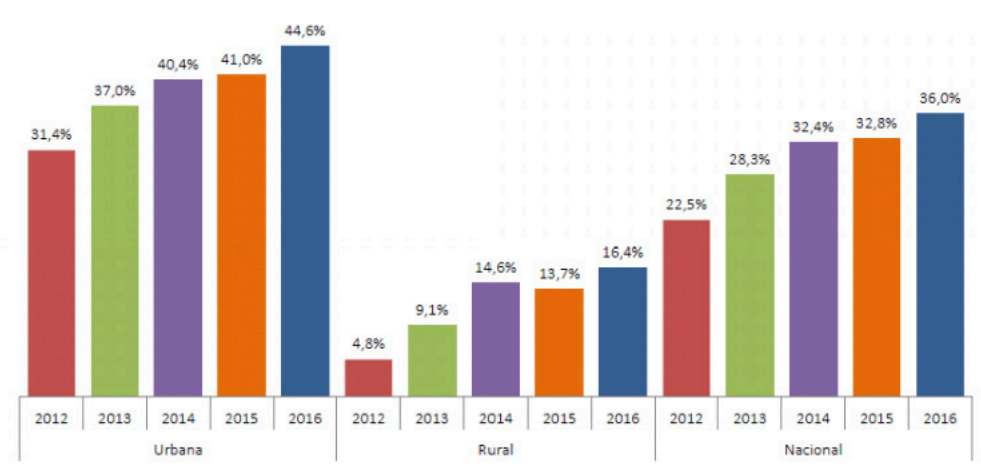

Figura 4. Acceso a internet según área.

Fuente: Encuesta Nacional de Empleo Desempleo y Subempleo - ENEMDU (2012 - 2016).

Con respecto a las personas que utilizan teléfonos inteligentes, también se muestra un alto crecimiento de más de 40 puntos en cinco años y la tendencia sigue en alza, el 56\% de la población tiene un celular activo como muestra la Figura 6.

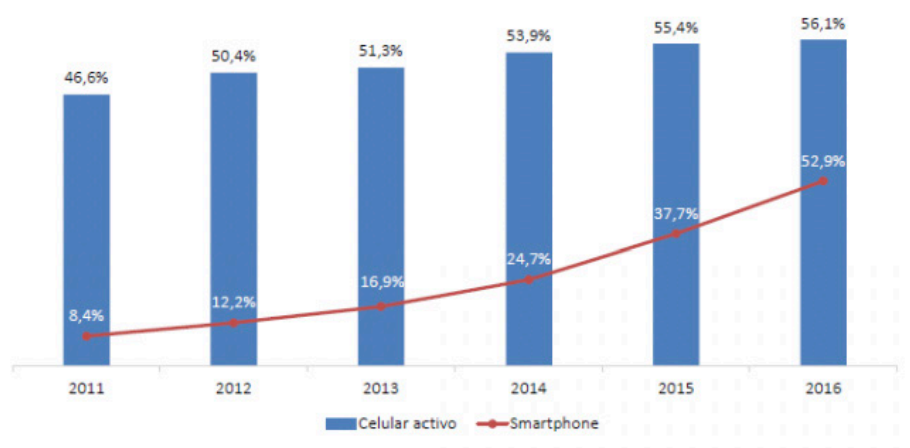

¿El (os) teléfono (s) celular (es) que (...) tiene es / son SMARTPHONE (teléfono Inteligente, se puede comunicar a través e-mails, etc.)?

Figura 5. Porcentaje de personas que tienen teléfono inteligente (SMARTPHONE) a nivel nacional. Fuente: Encuesta Nacional de Empleo Desempleo y Subempleo - ENEMDU (2012 - 2016).

Otras estadísticas importantes de acuerdo al INEC (2017) es que 36,0\% de los hogares tiene acceso a Internet, de ellos el 24,5\% accede a través de algún medio inalámbrico, el 78,9\% de los jóvenes entre 16 a 24 años afirmaron que utilizaron la computadora en el último año, le siguen los menores entre 5 a 15 años con el 63,4\% de su población. 
La Figura 6 muestra que Galápagos sus habitantes muestran el uso más alto de computadora en un 68,4\% y las provincias que siguen la tendencia son Pichincha, Azuay, Tungurahua y el Oro, constituyendo las cinco provincias que más usan computador.

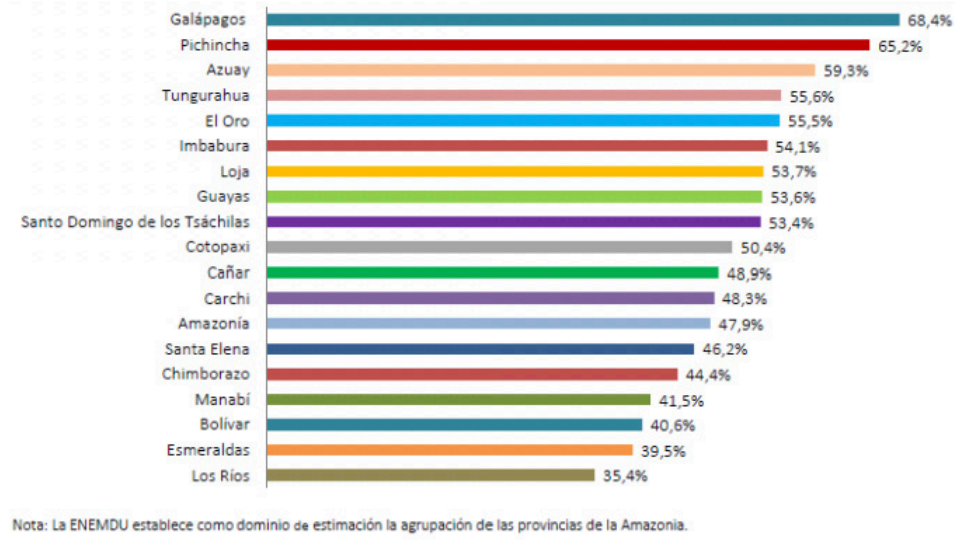

Figura 6. Porcentaje de personas que utilizan computadora por provincia en el 2016

Fuente: Encuesta Nacional de Empleo Desempleo y Subempleo - ENEMDU (2012 - 2016).

Finalmente, otro parámetro importante que determinó este estudio es la cantidad de personas analfabetas digitales, que se puede apreciar en la Figura 7, si bien la tendencia es decreciente a nivel nacional el porcentaje es de $11,5 \%$, urbano $6,9 \%$ y a nivel rural del $22 \%$ lo que nuevamente permite la apreciación de una oportunidad de mejora que acorte esa brecha.

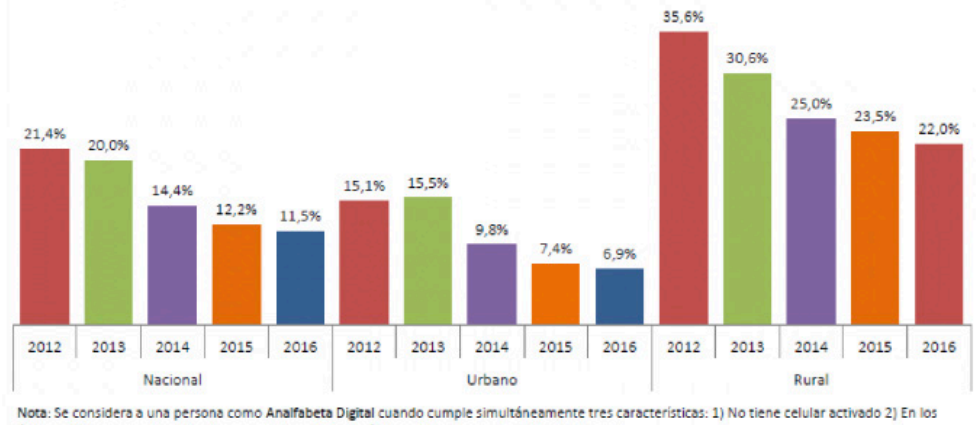

útimos 12 meses no ha utilizado computadora 3 ) En los úlitimos 12 meses no ha utilizado internet.

Figura 7. Porcentaje de personas analfacbetas digitales por área.

Fuente: Encuesta Nacional de Empleo Desempleo y Subempleo - ENEMDU (2012 - 2016). 
Las empresas multinacionales y también varios grupos empresariales ecuatorianos cuentan con infraestructura de sistemas integrados principalmente los ERP (Enterprise Resource Planning), los bancos también cuentan con valiosas bases de datos y estructuras informáticas el SRI con sus anexos transaccionales y la exigencia de facturación electrónica ha volcado aún más a las empresas a usar la tecnología e interconexión de sus procesos. Las pequeñas y medianas empresas son parte también de este proceso, pero los costos de inversión y la capacitación del talento humano son algunas de sus principales barreras, a pesar de ello, muchas usan software libre $(29,4 \%)$, correo electrónico y redes sociales, que ya les permiten estar conectadas con proveedores y clientes.

De acuerdo a los informes del INEG (2015), en el Ecuador el 66,7\% las empresas invierten en TIC, siendo sus sectores más representativos la manufactura y el comercio quedando una brecha importante a cubrir de más del 30\%. El comercio es que mayor inversión realiza con un 73,7\%, los dispositivos que más crecimiento han tenido son los smartphone, que en cuatro años han aumento de 10 puntos, también están otros dispositivos como PDA, tablets, etc., el 81,8\% de los dispositivos son computadores y notebooks lo que refleja el alto porcentaje de inversión para que los trabajadores usen computadora.

El uso de internet tambiéna ha tenido crecimiento llegando a usarse para las labores diarias en un $33.3 \%$ y casi el 97\% tienen servicio de internet de banda ancha fija. Solo un 13,9\% compra por internet y el 9,2\% realiza sus ventas por internet, esto permite un amplio campo de acción para aprovechar estos dos procesos a través de la red. Las estadísticas también muestran que el fax va cayendo en desuso desde $60 \%$ hasta un $35,2 \%$ en cuatro años, pero otros como los celulares, correo electrónico, redes sociales y otros van en aumento 97\%, 95\%, 58\% y 49\% respectivamente.

El Ecuador tiene mucho potencial para explorar principalmente en el ámbito de uso de internet, compras, ventas y medios de comunicación. La inversión es clave para que el uso de la tecnología llegue a todos los espacios de la sociedad en sus múltiples variantes y se tecnifique a la mano de obra y ciudadanía en general para potenciar su uso y fortalecer la economía digital en el Ecuador.

\section{CONCLUSIONES}

El principal reto para Ecuador y para Latinoamérica en general es procurar que todas las empresas acojan a la tecnología en sus procesos organizacionales cubriendo la brecha existente que persiste con los países desarrollados y que no ha permitido un mayor arranque hacia una nueva y renovada economía digital para los países en vías de desarrollo. 
Otra brecha por cubrir es la gestión digital del talento humano, ya que existen muchas personas sin la formación necesaria para enfrentar las nuevas tecnologías e imposibilitadas de usarlas de forma eficiente generando a su vez nuevos productos y servicios. Se debe trabajar en eliminar el analfabetismo digital presente en Latinoamérica.

Otro tema importante es el de la identidad digital, puesto que en Latinoamérica aún existen personas que no pueden demostrar su identidad y este es un reto para la economía digital, lograr la visualización de todos los ciudadanos del mundo y que puedan acceder a todos los productos y servicios que se le puedan proveer de forma digital. Es necesario inversión y seguimiento para lograr este objetivo.

Potenciar la infraestructura digital del país a través de inversión y aplicación de políticas para su desarrollo y apertura en esto actúan gobierno y sector privado para juntos fortalecer el crecimiento de una economía digital emergente, que requiere talento, investigación e inversión como ejes clave dentro de un marco regulatorio consistente con los objetivos como nación, principalmente con el potencial que tiene Ecuador para llegar a la industria 4.00 en sus sectores más importantes sociales y económicos. 


\section{REFERENCIAS BIBLIOGRÁFICAS}

Borrego, B. (2014). La necesidad de apliación de los tributos a las nuevas tendencias de los negocios electrónicos. Revista de Internet, Derecho y Política, (18), pp. 51-59. Recuperado de: http:/ / www.redalyc. org/articulo.oa? id $=78832841006$

Bostman, R. (2013). The Sharing Economy Lacks a Shared Definition.

Buenadicha, G., Canigueral, A. y De León, I. (2017). Retosy Posibilidades de la Economía Colaborativa en América Latina. Washington, Estados Unidos: Banco Interamericano de Desarrollo. Recuperado de: https://publications.iadb.org/handle/11319/8308

Doménech, G. (2015). La Regulación de la Economía Colaborativa (El Caso de Uber contre el taxi). Revista CEFLEGAL, pp. 61-104.

GREYGROUP. (2016). Tendencias digitales 2016/17. Madrid, España: GREY GROUP. Recuperado de: www.grey.es

Guzmán, J., Muñoz, J., Álvarez, F. y Velázquez, C. (2014). La brecha digital en el estado de Aguascalientes. Investigación y Ciencia, 22(61), pp. 54-61. Recuperado de: http://www.redalyc.org/ articulo. oa? id $=67431579008$

Hernández, K. (2017). Blockchain for development-hope or hype? Rapid Response Briefing, 4(17). Recuperado de: http:/ / opendocs.ids.ac.uk/opendocs/handle/123456789/12945

INEG. (4 de Diciembre de 2015). Instuto Nacional de Estadísticas y Censos. Recuperado de: http: / /www. goo.gl/LLw1Skcontent_copy

INEC. (1 de Diciembre de 2017). Instituto Nacional de Estadísticas y Censos. Recuperado de: http:// www.ecuadorencifras.gob.ec/sociedad-de-la-informacion/

Jiménez, M., Acosta, M. y Salas, L. (2017). Learnability como característica del ciudadano del siglo XXI. Revista Dominio de las Ciencias, pp. 54-71. doi: http://dx.doi.org/10.23857/dom.cien. pocaip.2017.3.4.jul. 54-71

Kassan, J. y Orsi, J. (2012). The legal landscape of the sharing economy. Fournal of Environmental Law and Litigation, pp. 1-20.

La Nueva Economía Digital. (2017). Washington, Estados Unidos: BID. 
Lombardero, L. (2015). Trabajar en la Era Digital. España: LID Editorial Empresarial. Recuperado de: http://trabajareradigital.com

López, C. (2016). Tendencias. Recuperado de: http://www.dinero.com/pais/articulo/colombia-essegundo-en-ranking-de-economia-digital-de-telefonica/231518

Mossberger, K., Tolbert, G. y McNeal, R. (2008). Digital Citizenship. Cambridge, Estados Unidos: MIT Press.

Pareja, A., Pedak, M., Gómez, G. y Barros, A. (2017). La Gestión de la Identidad y su Impacto en la Economía Digital. Washington, Estados Unidos: Banco Interamericano de Desarrollo. doi:http:// dx.doi.org/10.18235/0000786

Porras, M. (2017). ¿Qué deben hacer los gobiernos para convertirse en digitales? Washington (Estados Unidos): BID.

Schwab, K. (2016). La cuarta revolución industrial. Madrid, España: Penguin Randon House.

Zhao, F., Wallis, J. y Singh, M. (2015). E-government development and the digital economy: a reciprocal relationship. Internet Research, 25(5), pp. 734-766. doi:http://dx.doi.org/doi.org/10.1108/ IntR-02-2014-0055 
/03/ 


\section{CONTRIBUCIONES ECONÓMICAS ANCESTRALES SUSTENTADAS EN LA CAÑA GUADUA EN JIPIJAPA \\ - MANABÍ - ECUADOR \\ ECONOMIC CONTRIBUTIONS CUSTOMS BASIC IN THE BAMBOO CANE OF JIPIJAPA - MANABÍ - ECUADOR}

Robards-Javier Lima-Pisco

Universidad Estatal del Sur de Manabí. Ecuador. E-mail: robardslima@gmail.com ORCID: https://orcid.org/0000-0001-7743-6046

Alberto Rodríguez Rodríguez

Universidad Estatal del Sur de Manabí. Ecuador. E-mail: drrodriguezcc9564@gmail.com ORCID: https://orcid.org/0000-0003-4395-4202

Miguel Ángel Padilla Orlando

Universidad Estatal del Sur de Manabí. Ecuador. E-mail: miguel08012011@hotmail.com ORCID: https://orcid.org/0000-0001-5242-8461

Adis Anicia Luna Báez

Universidad Estatal del Sur de Manabí. Ecuador. E-mail: albarlunalia@gmail.com ORCID: https://orcid.org/0000-0001-6260-3454

Recepción: 02/04/2018. Aceptación: 30/05/2018. Publicación: 24/08/2018

Citación sugerida:

Lima-Pisco, R.-J., Rodríguez Rodríguez, A., Padilla Orlando M. Á. y Luna Báez, A. A. (2018). Contribuciones económicas ancestrales sustentadas en la caña guadua en Jipijapa-Manabí-Ecuador. 3 C Empresa: Investigación y pensamiento crítico, 7(3), 44-59. DOI: http://dx.doi.org/10.177993/3cemp.2018.070335.44-59/ 


\section{RESUMEN}

En el Ecuador, provincia de Manabí cantón Jipijapa, en la década de los años 70 se produce un éxodo, a otras ciudades del país, trayendo consigo la pérdida de conocimientos tradicionales asociados con la agricultura, y todo tipo de formas de trabajo comunitario. Este trabajo tiene como objetivo rescatar las costumbres ancestrales, para mejorar la economía y el medio ambiente del cantón Jipijapa, generando bioconocimiento, para proteger, recuperar, catalogar, socializar, tradiciones de saberes ancestrales, innovación y producción de bienes ecosistémicos, mediante el diálogo de saberes y la participación de los generadores de estos conocimientos. Esta investigación se ha apoyado en los métodos de análisis bibliográfico, el inductivo- deductivo, el analítico - sintético y de observación.

\section{ABSTRACT}

In Ecuador, province of Manabi canton Fipijapa, in the 1970s there was an exodus to other cities in the country, bringing with it the loss of traditional knowledge associated with agriculture, and all kinds of forms of community work. This work aims to rescue ancestral customs, to improve the economy and the environment of the Fipijapa canton, generating bio-knowledge, to protect, recover, catalog, socialize, traditions of ancestral knowledge, innovation and production of ecosystem goods, through the dialogue of knowledge and the participation of the generators of this knowledge and knowledge. This research has relied on methods of bibliographic analysis, inductive-deductive, analytical-synthetic and observation.

\section{PALABRAS CLAVE}

Agricultura, Bioconocimientos, Ecosistémicos, Éxodo.

\section{KEY WORDS}

Agriculture, Bio-Knowledge, Ecosystems, Exodus. 


\section{INTRODUCCIÓN}

La diversidad cultural establece que los saberes tradicionales y ancestrales son un patrimonio cuyo valor no se enclaustra únicamente a las comunidades originarias, sino que dichos saberes constituyen un significativo recurso para toda la humanidad. En tanto, enriquecen el conocimiento mutuo por medio del diálogo, y permiten conservar la amplia visión de la diversidad cultural existente en un territorio (UNESCO, 2001).

Según se asevera en la declaración, la diversidad cultural es una fuente de creatividad y de innovación, su reconocimiento promueve la inclusión social y la participación, que debe ser protegida, promovida, reconocida y consolidada en beneficio de toda la humanidad de las generaciones presentes y futuras. La diversidad cultural amplía las posibilidades de elección que se brindan a todos, y que es una fuente de desarrollo, no solamente en términos de crecimiento económico, sino también como medio de acceso a una existencia intelectual, afectiva y satisfactoria.

Es necesario reconocer las diversas expresiones culturales que existen y han existido, y en este ámbito, resulta notable el esfuerzo que se ha hecho en el Ecuador donde, en el marco del proyecto histórico del Sumak Kawsay o Buen Vivir, se fomenta el rescate, la preservación y la divulgación de los conocimientos ancestrales. La identidad es una cualidad de ser, de sentir e interpretar al mundo, un legado que se adopta, una construcción social y por tanto, cambiante. Afirma Goldsmith, (1999), editor de la Revista The Ecologist, que el mundo natural ha sido sustituido por el mundo sustitutorio o segunda naturaleza. Por lo tanto, la naturaleza ha desaparecido como espacio no humano. La naturaleza ha sido abolida (Blûhdorn, 2000) y lo que nos rodea es definitivamente un producto de la civilización.

La naturaleza, virgen, intocada y no hallada por el ser humano (Aledo, 2002), ha ido desapareciendo con el avance del "progreso". Los espacios naturales no modificados por la acción antrópica se han visto reducidos en su extensión hasta casi desaparecer debido a la expansión de la especie humana. El mundo natural de los "conservacionistas" ha sido sustituido por un mundo post- natural (Mckibben. 1990). La extensión del urbanismo y la industrialización, la modificación de los espacios naturales por la actividad agrícola y la deforestación, el alcance mundial de las diferentes formas de contaminación, el efecto global del cambio climático han terminado por alterar cualquier resto de espacio natural para convertirlo en un espacio humanizado, un mundo artificial.

No obstante, las presiones sociales y medioambientales, hace que los pueblos y comunidades, depositarios activos de los conocimientos y sabiduría ancestrales, se enfrentan al riesgo permanente 
de su propia sobrevivencia debido a la amenaza de políticas públicas extractivas de los recursos naturales por el mismo Estado y ejecutadas por las instancias públicas o sectores privados que se filtran sobre la sobrevivencia cultural de las comunidades y pueblos, incluso planteadas desde los modelos del socialismo del siglo XXI o el socialismo del Buen Vivir.

Es importante una construcción horizontal, mucho más sólida, en la que participan todos los actores sociales, aunque el modelo civilizatorio dominante, la crisis ambiental y la ética del conocimiento y diálogo de saberes son parte de un conocimiento económico, tecnológico y cultural que ha depredado a la naturaleza y negado a los conocimientos ancestrales.

Degradar el ambiente, subvalorar la diversidad cultural y excluir las costumbres ancestrales, mientras se privilegia un modo de producción y un estilo de vida insustentables se han convertido hegemónicos en el proceso de globalización. Las presiones sociales y medioambientales externas, las migraciones, la invasión de los modos de vida modernos y la confusión de las formas de vida propia debilitan la preservación de la naturaleza así como la transmisión de conocimientos tradicionales a las presentes y futuras generaciones.

La crisis ambiental no es una crisis ecológica, sino social, una problemática mundial, de la que ya ningún país escapa, que compromete no solo a los gobiernos, sino a la misma población en la exploración de alternativas frente a sus efectos (Anzolín, 2007). Es el resultado de una visión mecanicista del mundo que, ignora los límites biofísicos de la naturaleza y los estilos de vida de las diferentes culturas, acelerando el calentamiento global.

Es que la crisis ecológica se da cuando el ambiente de una especie o de una población sufre cambios críticos que desestabilizan su continuidad. Entre las causas están: un cambio abiótico (por ejemplo, incremento de la temperatura o bajo nivel de lluvias), la presión de la depredación o la sobrepoblación.

En el diálogo de saberes todos los pueblos del mundo han pasado por diversos procesos en la construcción de su propia sabiduría y su propio modo de pensar y actuar, se trata de una racionalidad y una lógica que funciona al interior de cada cultura.

Esta investigación se sustenta en saberes y conocimientos ancestrales, a partir de elementos importantes: clarificación de saberes locales y conocimientos ancestrales de los pueblos, de la comunidad a partir de los términos empleados por los técnicos ambientalalistas de los pueblos, relación de empatía que guardan los animales, las plantas, los astros, las estaciones climáticas con 
respecto al cuidado y cultivo para respetar la diversidad, acrecentar el mejoramiento de la calidad de los productos con conservación de semillas ancestrales para el consumo familiar y mercado.

Es importante saber también las características y elementos que comprende el calendario agro festivo comunitario. Además, se puede encontrar el proceso, las estrategias de educación ambiental dados de acuerdo a su percepción, de la misma manera la educación ambiental formal desde la visión de conservación del ambiente sano con justicia ecológica (Tapullima, 2014).

El Calendario Agro festivo es una herramienta metodológica donde se insertan los elementos de un diálogo de saberes, su valor es un aporte a la educación ambiental que revalora y respeta los saberes locales desde la comunidad hacia la convivencia armónica con todos los seres del cosmo evitando la contaminación, y a perspectiva de producción agroecológica que responde a los ciclos naturales y sociales. $\mathrm{Al}$ ordenar en el tiempo y el espacio: las relaciones tradicionales de producción, las ferias y las fiestas, los territorios, los alimentos, entrelazados y marcados por el caminar cíclico del sol y la luna (Guilcamaigua y Chancusig 2009).

\section{COMPONENTES DEL CALENDARIO AGROFESTIVO}

El ciclo productivo y ritual, está caracterizado por ser cíclico y holístico y además se presenta de manera natural y sin separar la totalidad con que se presenta de la vivencia (familia, comunidad) (Rengifo, 2008).

\section{a. Tiempo}

Es la parte central del calendario donde se representa el paisaje de la comunidad, con su producto principal de cultivo.

\section{b. Períodos climáticos}

Tipos de climas bien definidos, uno por la presencia de lluvias y la otra por ausencia de las mismas.

Como investigadores, cabe indicar que forma parte de la historia del Ecuador, el cultivo de guadua, más conocida como "caña guadua", "caña brava", o simplemente como caña, su nombre científico guadua Angustifolia Kunt, reconocible por la banda blanca alrededor del nudo y sus espinas en las ramas, pertenece a la numerosa familia de los bambúes existentes en la naturaleza. Es conocida y usada desde la época precolombina hasta nuestros días, está identificada con todos los grupos humanos, por sus valores sociales, culturales, económicos y ecológicos ambientales. Sin embargo, 
existen otros modos de producción de saberes y conocimientos que han construido los distintos pueblos originarios del mundo, al que la ciencia moderna descalifica nominándolos como empíricas, tradicionales, ancestrales, provenientes del campo.

La preservación de los saberes y conocimientos que poseen los ancianos/as, comunidades, como instrumento poderoso de conocimiento hacia la transformación de la naturaleza, con capacidad para resolver problemas críticos y ser capaz de trascender el reconocimiento de los límites y potenciales de la naturaleza, así como la complejidad ambiental, a enfrentar los desafios de la humanidad, promueve una alianza naturaleza-cultura, sustentada en una ética de la sustentabilidad en valores, creencias, sentimientos y saberes.

Hoy en día, el crecimiento económico debe ser el camino para conseguir el desarrollo continuo que traspase los ámbitos económico o político y se implemente en lo más profundo de las consciencias de las personas, porque el crecimiento es sinónimo de éxito, es el origen del interés sobre la viabilidad de las artesanías en guadua.

El cambio medioambiental tiene "una dimensión ética, entre las que se destacan las causas últimas de la crisis ambiental actual por el modo de relación establecido por la sociedad industrial con el mundo natural" (Pérez, 2014).

Bajo esta perspectiva, las ciencias contribuyen a identificar y caracterizar las causas próximas de la crisis ambiental. Esto involucra esencialmente una respuesta ética, sujeta a procesos de conflicto y deliberación entre diversos actores sociales con intereses y valores contrastantes.

Se propone una aproximación ética alternativa entre lo que se debe hacer (derivado de la ética) y lo que puede hacer (derivado de la ciencia). Esta aproximación es central en la interrelación entre los modos de investigar la naturaleza y los modos de habitar en ella, al respecto.

En esta dinámica interdisciplinaria, las ciencias ecológicas asumen un papel crucial en motivar cambios éticos en los modos de relación entre la sociedad contemporánea y la biosfera fundados en cambios en los modos en que los seres humanos perciben, conocen y comprenden ecológicamente la naturaleza.

Los saberes y conocimientos ancestrales sustentan el significado recurso para la humanidad, la visión de la diversidad natural y cultural hacia la inclusión social y su aporte y cuidado ambiental en la economía. Se considera producto de la enseñanza y práctica constante de la vida comunitaria, y no son las relaciones solamente entre seres humanos, sino con todos los elementos que constituyen y 
complementan la vida integral. Los espacios de transmisión de los saberes distan de infraestructuras complejas y de seres especializados. Los reforzamientos de los saberes se dan de manera constante desde los conocimientos ancestrales, permitiendo un entendimiento amplio de la vida y de lo importante para mantener el equilibrio espiritual y material que reclama la Pachamama-Naturaleza, y los seres humanos.

Así, las nacionalidades y pueblos, en especial Jipijapa perteneciente a la provincia de Manabí Ecuador está inmersa en las entidades políticas e históricas constituidas antes de los procesos de la conquista territorial, política, ideológica y económica sobre la base de su saber ancestral.

Los saberes ancestrales son un campo muy amplio, y una forma de abordar es la que hace la academia, que toma el saber ancestral como si se tratara de un objeto colgado en el árbol del tiempo, sin tener en cuenta a los pueblos que los concibieron y desplazando absolutamente a los hombres y mujeres que ha dedicado toda su vida a resguardar y mantener vigente dichos saberes, y lo toman como cualquier otro objeto manipulable para beneficio del mercado capitalista.

Sobre las nacionalidades y pueblos queda en la básica descripción de culturas existentes en el Ecuador, como una presencia de la diversidad sin perspectivas políticas ni históricas para los pueblos la existencia de los saberes ancestrales tiene que ver con el cuidado ambiental en la economía de los pueblos en especial de Jipijapa.

Los activos conocimientos ancestrales se enfrentan al riesgo permanente de su oportuna sobrevivencia debido a la amenaza de políticas públicas extractivas de los recursos naturales por el mismo Estado y ejecutadas por las instancias públicas o sectores privados que se filtran sobre la sobrevivencia cultural, porque las presiones sociales y medioambientales externas, las migraciones, la invasión de los modos de vida modernos y el desbaratamiento de las formas de vida propia debilitan la preservación de la Naturaleza - o Pachamama - así como de transmitir los conocimientos tradicionales a las presentes y futuras generaciones.

\section{1. ÉTICA DEL CONOCIMIENTO Y DIÁLOGO DE SABERES}

Hoy en día el avance científico es parte de una ideología del progreso económico y del dominio de la naturaleza, privilegiando modelos mecanicistas y cuantitativos de la realidad que ignoran las dimensiones cualitativas, subjetivas y sistémicas que alimentan otras formas del conocimiento.

El fraccionamiento del pensamiento científico lo ha inhabilitado para comprender y abordar los problemas socioambientales complejos. Las ciencias y la economía han sido efectivas para intervenir 
sistemas naturales y ampliar las fronteras de la información, sin embargo, no se han traducido en una mejoría en la calidad de vida de la mayoría de la población mundial; muchos de sus efectos más perversos están profundamente arraigados en los presupuestos, axiomas, categorías y procedimientos de la economía (Rengifo, 2008).

En correspondencia al cómo, éste hace referencia a las actividades o formas de actuar y el dónde señala el espacio físico donde tienen lugar esas actividades, caso especial, el medio ambiente, que desde varias décadas tiene que ver con fomentar el desarrollo económico, y eso tiene un efecto concreto en el medio ambiente: lo transforma.

Aunque no se debe generalizar, lo cierto es que el paso del tiempo ha demostrado que el modelo económico vigente se caracteriza por una explotación excesiva de los recursos naturales y por generar altos niveles de contaminación al medio ambiente, por lo tanto, el hombre transforma el medio de una manera negativa. Se destruyen montañas para extraer minerales, se talan bosques para conseguir madera, se sobreexplotan los acuíferos, se extinguen especies animales, se llena el aire de gases tóxicos.

El conocimiento ancestral a través de nuestros antepasados es el conocimiento y dominio perfecto del uso, mantenimiento y mejoramiento de la tierra para sus diferentes cultivos, utilizando la construcción de acequias para el drenaje y canales para el riego. Sus herramientas para romper el suelo, el arado, el mismo que no ha cambiado en mayor grado, desde hace unos 60 años, y que consiste en un instrumento de madera liviana y un yugo, permite arar y sembrar.

Hoy en día, es importante reconocer que la caña guadua está al borde del olvido, tristemente oculta bajo el abandono y la pobreza, cuando la tecnología rehúsa reconocer las maravillas de este material. Su importancia económica para el Ecuador va más allá de su uso artesanal. Por ejemplo, es indispensable para el cultivo del banano, uno de los principales rubros de exportación, y es vital para la industria bananera, camaronera o las plantaciones de flores. Además, son especies forestales importantes en la conservación de suelos, calidad de aguas, manutención y refugio de una variada avifauna, producción de material para la construcción, artesanía, elaboración de papel, alimentación humana.

Si no fuera por las bondades de este material, el impacto ecológico de dichas actividades sería aún mayor del que se tiene actualmente, considerando que su aporte en el desarrollo cultural y económico del país especialmente de Jipijapa, es de gran valor, siendo uno de los recursos naturales renovables con que se cuenta e importante en la economía de subsistencia nacional, y es común 
ver guadua en todo lado, pero es menos evidente que las personas tomen conciencia de aprender a cosecharla ya que el hombre lo más factible es deforestar.

Este material se lo puede apreciar en gran cantidad en el sitio La Mona, cantón Jipijapa, en donde los agricultores son las personas más experimentadas sobre su cultivo y corte. La capacidad que tienen nuestros ancestros de entender a la naturaleza es impresionante porque saben si va a ser buena o mala la cosecha desde el momento de la siembra.

El cumplimiento con los objetivos de buscar un tiempo más de vida útil a la madera y caña aplicando costumbres ancestrales, como ejemplo mirar las estaciones de la luna para poder cortar un árbol. Es decir, la conversación con la luna es frecuente sobre todo en luna creciente, momento apropiado para la siembra, este tiempo casi siempre coincide con una de las fiestas de los santos en septiembre con las fiestas de la virgen de Mercedes, octubre San Francisco y en diciembre con las fiestas de Purísima Concepción de María, tomándose de sagrado y de peregrinación.

Es necesaria una reflexión sobre cómo funciona el mundo hoy en día, hacer conciencia crítica a las personas, no solo por preservar el medio desde una posición ecologista, sino para salvaguardar el propio bienestar, porque contaminar el medio es una grave irresponsabilidad, y debido a que el sistema de producción y de consumo actual es propicio contaminar la naturaleza (Valladolid, 2018).

En jipijapa, el escaso conocimiento o la no aplicación de costumbres ancestrales en el corte o tala de madera y/o caña guadua, está acelerando la degradación de los suelos, la perdida de cuencas hidrográficas junto con la contaminación ambiental, la destrucción de eco sistemas, la desaparición de algunos tipos de arborización (ECUABAMBU, 1978), ocasionados por la deforestación ha creado la imperiosa necesidad en tratar de mitigar estos impactos, mismos que si no se hace algo y con urgencia se estará deteriorando el medio ambiente (ECUABAMBU, 2007).

Las personas que viven en el sitio "La Mona" son habitantes originales de numerosas áreas que hoy se encuentran protegidas y/o restringidas para cuantiosas actividades que se consideran nocivas al entorno natural y estas poblaciones poseen conocimientos ancestrales y aplicación de las estrategias de explotación y aprovechamiento de la naturaleza, al tiempo que se practican funciones conservacionistas en favor del medio ambiente. No en sí por sencilla idea de conservación, sino por tener el conocimiento y la plena conciencia de que una sobre explotación del recurso, tendría repercusiones no solamente en la naturaleza, su entorno y el paisaje, sino que compromete su propia subsistencia futura. 
Los miembros de la comunidad con conocimientos ancestrales están conscientes del delicado equilibrio que existe entre los distintos seres, esto se puede percibir al analizar el hecho de que la ideología de muchos de estos pueblos, especialmente del sitio "La Mona" se basa en el principio de que existe una afinidad entre los humanos y el resto de los seres que habitan en la Tierra (Señas, Agroastronomía, 2010).

Hoy en día se puede afirmar que las culturas autóctonas han participado de manera activa en la conservación del ambiente en general y de la biodiversidad, por lo que resulta de vital importancia que tales poblaciones se mantengan en sus lugares de origen de modo que sus costumbres ancestrales ayuden en la protección de áreas naturales protegidas y aporten en la economía del país.

\section{METODOLOGÍA}

El presente estudio se desarrolló en el período 2016 - 2017, donde se aplicaron los métodos: científico, bibliográfico, empírico, inductivo - deductivo, y las técnicas de la observación, entrevista y encuesta a miembros de comunidades campesinas de la zona sur de Manabí, las cuales fueron aplicadas a 25 personas que oscilan en edad de 40 a 64 años, tanto a hombres como a mujeres.

A partir de los resultados, se pudo determinar, en la Tabla 1, las ventajas de la utilización de las fases de luna en el corte de caña guadua en un 100\%, la durabilidad con aplicación de costumbres ancestrales 10 años en un 80\%, el corte de caña guadua de manera industrial inadecuada afecta el medio ambiente en un 100\%, el 100\% indica que el calendario agrofestivo comunitario de la comunidad de Jipijapa sistematiza la actividad productiva a agrícola, las costumbres ancestrales son parte vital en el fortalecimiento del Sumak Kawsay en un 92\%, la utilización de caña guadua en construcción, adornos, edificación de casas, cercos aportan en la economía de Jipijapa.

Tabla 1. Relaciones, costumbres ancestrales, manejos y aplicaciones.

\begin{tabular}{|c|c|c|}
\hline Alternativas & Cantidad & Porcentaje \\
\hline Ventajas en utilización de las fases de luna en el corte de caña guadua. & 25 & $100 \%$ \\
\hline 10 años de durabilidad con aplicación de costumbres ancestrales & 20 & $80 \%$ \\
\hline Corte de caña guadua de manera industrial inadecuada afecta el medio ambiente. & 25 & $100 \%$ \\
\hline El calendario agrofestivo comunitario sistematiza la actividad agrícola & 25 & $100 \%$ \\
\hline Las costumbres ancestrales son parte vital en el fortalecimiento del Sumak Kawsay. & 23 & $92 \%$ \\
\hline $\begin{array}{l}\text { Utilización de caña guadua en construcción, adornos, edificación de casas, cercos aportan en la } \\
\text { economía de Jipijapa. }\end{array}$ & 25 & $100 \%$ \\
\hline
\end{tabular}

Fuente: fuentes de la Investigación. 


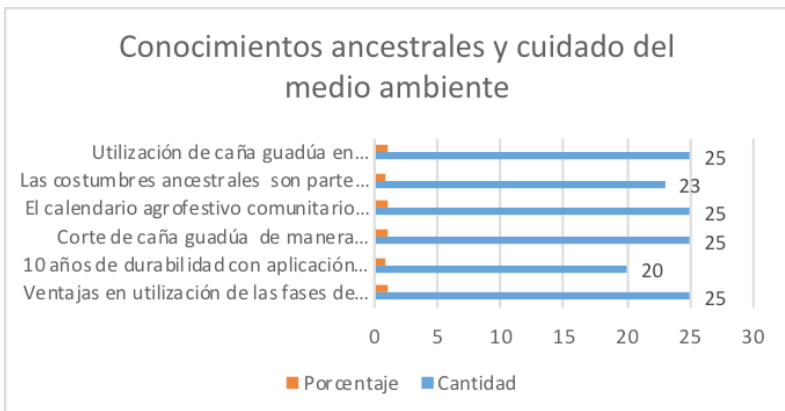

Gráfico 1. Conocimientos ancestrales y cuidado del medio ambiente.

Fuente: elaboración propia.

\section{RESULTADOS}

Visibilizar saberes y prácticas ancestrales, partiendo de su cosmovisión en la comunidad.

Discutir y explorar el término Sumak Kawsay adoptado por el sistema y legislación Nacional y que termina desvirtuando su contenido, porque en la práctica no se toma en cuenta la diversidad de cultura existente en el país, imponiendo culturas industrializadas que deterioran el medio ambiente.

Realizar prácticas de saberes ancestrales tradicionales en la plantación y cortes de caña guadua por ejemplo.

Concientizar a los campesinos sobre la importancia en la aplicación de estas costumbres para evitar la deforestación e inclusive la perdida de cuencas hidrográficas.

\section{CONCLUSIONES}

La transmisión de conocimientos y saberes ancestrales es parte de los la cultura defensora del patrimonio cultural intangible y continúa vigente en Jipijapa, especialmente en el sitio La Mona.

El calendario agrofestivo comunitario y religioso sistematiza las actividades productivas agrícolas, la agroastronomía entre otras recupera sabiduría ancestral que es de vital importancia en el fortalecimiento del Sumak Kawsay y apoyar a la educación ambiental con justicia ecológica.

El corte de caña guadua, teniendo como guía el calendario agrofestivo y las fases de la luna, revaloriza las señas, secretos, fiestas, el aporte de educación ambiental ayuda a conservar el ambiente libre de contaminación y a la economía de Jipijapa. 


\section{ANEXOS}

\subsection{LOCALIZACIÓN Y SUPERFICIE}

Jipijapa se encuentra ubicado al sur de la provincia de Manabí. En la franja costera del Ecuador. Sus coordenadas son: $1^{\circ} 20^{\prime}$ Latitud Sur y $80^{\circ} 35^{\prime}$ Longitud Oeste.

\section{Limita al:}

Norte con los cantones: Montecristi, Portoviejo y Santa Ana.

Sur con el cantón: Paján y la provincia del Guayas.

Este con el cantón: 24 de Mayo y Paján.

Oeste con el: Océano Pacifico y el cantón Puerto López.

Su superficie es de $1.420 \mathrm{Km} 2$.

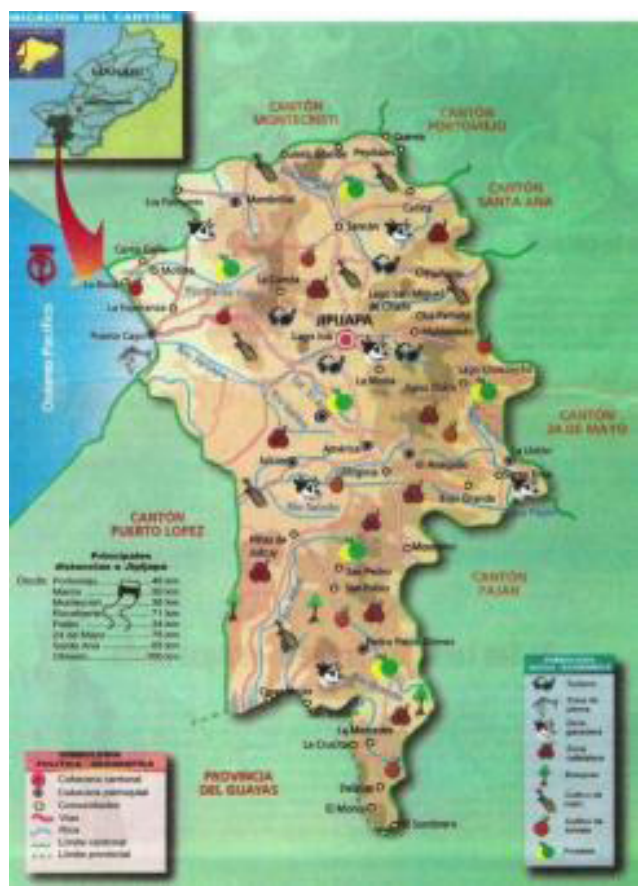

Figura 1. Situación Geográfica del Cantón Jipijapa. 


\section{REFERENCIAS BIBLIOGRÁFICAS}

Aledo, A. (2007). La crisis ambiental y su interpretación sociológica. Universidad de Alicante.

Anzolín, R. (2007). Rastreando los orígenes de la actual crisis ambiental. Ecoportal. Net.

Blûhdorn. (2000). Real Green: Sustainability after the end of nature. San Juan, Puerto Rico.

ECUABAMBU. (1987). Proyecto de reforestación con caña guadua.

Gardiner, F. (2011). A perfect moral storm. The Ethical tragedy of climate change. Oxford, Reino Unido: University press.

Goldsmith, E. (1999). El Tao de la Ecología: Una visión ecológica del mundo. Barcelona, España: Icario.

Guilcamaigua D. y Chancusig E., (2009). Agroecología. Prácticas agricultura convencional.

Kwiatkowska, T. y López, R. (2013). Ingeniería genética y ambiental. México D.F., México: Plaza y Valdez Editon.

Mckibben. (1990). Environmental. Humanity's relationship with nature. Boston.

Núñez, M. (2013). La raíz de la base productiva está en la agricultura campesina. Entrevista. Diario El Telégrafo.

Oliveira, L., Luque D. y Núñez, M. (2002). Una ética para la sustentabilidad. Manifiesto por la vida. México D.F., México.

PATREG. (2006). Dirección de cambio climático en Ecuador. INAMHI. Instituto nacional de meteorología e hidrología. Ecuador.

Pérez, J. (2014). Crecimiento económico y conservación del medio ambiente. Recuperado de: http:// elordenmundial.com/cultura-y-sociedad/crecimiento-economico-y-conservacion-del-medioambiente/

Rengifo. (2008). La recuperación del respeto. Educación y Diversidad Cultural. Lima, Perú: EIRL.

Rengifo. (2009). Cosmovisión andina. Lima, Perú: S. edt.

Rozzi, R. (2016). Etica ambiental: raíces y ramas latinoamericanas. En R. Primack, R. Rozzi, P. 
Feinsinger, R. Dirzo y F. Massardo (Eds.) Fundamentos de Conservación Biológica: Perspectivas Latinoamericanas (pp. 311-359). México D.F., México: Fondo de Cultura Económica.

Rozzi, R. (1999). The reciprocal links between evolutionary-ecological sciences and environmental ethics. BioScience.

Señas., Agroastronomía. (2010). Proyecto Andino de tecnologías campesinas. Lima, Perú: Kawsay Mama.

Tapulima, E. (2014). Iniciativa para la conservación en la Amazonía andina. Unidad de apoyo ICAA.

UNESCO. (2001). Declaración Universal de la UNESCO sobre la diversidad cultural.

Valladolid. (2008). Importancia de la conservación In situ de la diversidad y variabilidad de plantas nativas cultivadas y sus parientes silvestres y culturales en la región andina- amazónica del Perú. Lima, Perú: Kawsay Mama. 
Ed. 35. Vol.7 N N 3. Agosto-Noviembre 2018
Dol: httpp///dx.doi.org/10.17993/3cemp.2018.070335.44-59/ 
/04/ 


\section{LA GESTIÓN DE PROCESOS ESBELTOS COMO PRINCIPIO DE MEJORA. UN CASO APLICADO A UNA COMERCIALIZADORA \\ LEANPROCESSESMANAGEMENTASAPRINCIPLEOF IMPROVEMENT. A CASE APPLIED TO A COMMERCE}

Dra. Ingeniera Industrial. Docente, Instituto Tecnológico de Sonora. Obregón, Sonora (México).

E-mail: bcarballom@gmail.com ORCID: https://orcid.org/0000-0003-0966-7146

Alejandro Arellano-González

Dr. Ingeniero Industrial. Docente, Instituto Tecnológico de Sonora. Obregón, Sonora (México).

E-mail: aarellanog@gmail.com ORCID: https://orcid.org/0000-0002-6594-8391

Nidia Josefina Ríos-Vázquez

Dr. Ingeniero Química. Docente, Instituto Tecnológico de Sonora. Obregón, Sonora (México).

E-mail: nidia.rios@itson.edu.mx ORCID: https://orcid.org/0000-0002-9134-7135

Recepción: 30/05/2018. Aceptación: 20/06/2018. Publicación: 24/08/2018

Citación sugerida:

Carballo-Mendívil, B., Arellano-González, A. y Ríos-Vázquez, N. J. (2018). La gestión de procesos esbeltos como principio de mejora. Un caso aplicado a una comercializadora. 3C Empresa: Investigación y pensamiento crítico, 7(3), 60-81. DOI: http://dx.doi.org/10.177993/3cemp.2018.070335.60-81/ 


\section{RESUMEN}

Se presenta el diseño de un sistema empresarial que promueve la gestión del proceso principal de una empresa comercializadora, al establecer actividades de planeación, monitoreo y control de indicadores. Asimismo, para orientar a esta empresa a un sistema de mejora continua, se implementan herramientas bajo una filosofia esbelta a nivel estratégico y operativo, atendiendo a los requerimientos que le plantea su entorno, su estrategia corporativa y las expectativas del cliente. Como resultado, la implementación del sistema de gestión de procesos propuesto para la empresa, promueve el aprovechamiento de las tecnologías tanto para el beneficio de los procesos internos para que estos sean eficientes, como para generar información que permita tomar mejores decisiones estratégicas que impacten en la competitividad de la empresa.

\section{ABSTRACT}

The design of a business system that promotes the management of the main process of a trading company is presented, by establishing activities of planning, monitoring and control of indicators. Also, to guide this company to a system of continuous improvement, tools are implemented under a lean philosophy at a strategic and operational level, meeting the requirements of its environment, its corporate strategy and customer expectations. As a result, the implementation of the process management system proposed for the company, promotes the use of technologies both for the benefit of internal processes to make them efficient, and to generate information to make better strategic decisions that impact on the competitiveness of the company.

\section{PALABRAS CLAVE}

Enfoque de procesos, Gestión, Diseño de sistemas, Mejora, Herramientas lean.

\section{KEY WORDS}

Process approach, Management, Systems design, Improvement, Lean tools. 


\section{INTRODUCCIÓN}

En la actualidad, las organizaciones tienen un reto mayor al que han tenido en el pasado para lograr los resultados que se esperan de ellas, esto debido en gran medida a la velocidad en que ocurren los cambios en materia de Ciencia y Tecnología, y el impacto que estos tienen no sólo en la naturaleza, sino también en la sociedad.

Las empresas específicamente tienen el reto de ser rentables y competitivas en este entorno caótico, donde los clientes cada vez exigen más por su dinero y tienen diversidad de opciones para cubrir sus necesidades en un mundo globalizado. Esto obliga a que adopten un pensamiento holista que asegure que se estudien todas las variables que afectan a su macro y micro entorno.

Competir en estas condiciones no sólo requiere que las empresas, en sus esfuerzos por prepararse para afrontar los cambios que transforman aceleradamente a la sociedad, actualicen su tecnología para mejorar sus procesos operativos y habiliten al personal en su uso, sin que ello afecte al servicio que ya le ofrecen a los clientes, sino que además es necesario que preparen su sistema de gestión para asegurar que estos esfuerzos de transformación no sean eventos aislados y obedezcan a un plan orientado a satisfacer al cliente y otras partes interesadas.

En la literatura se reportan diversos modelos, filosofias, técnicas y herramientas que promueven lo anterior, tal como el enfoque de procesos y la mejora continua que se incluye en la norma ISO 9001 (2015) o la filosofía esbelta ("lean") que engloba diversas herramientas bajo el enfoque de la mejora continua en sistemas de producción y servicio, a través de la disminución de despilfarro de todo tipo (Rojas-Jauregui y Gisbert-Soler, 2017; Sanz-Horcas y Gisbert-Soler, 2017).

Sin embargo, antes de aplicar este tipo de herramientas, es necesario que la empresa diseñe sus procesos, tal como lo ha promovido la reingeniería (Pérez-Andrés, Gisbert-Soler, y Pérez-Bernabeu, 2017), considerando los principios extraídos de la Teoría General de Sistemas de Bertalanfy (1968), que ha sido promovida para su aplicación en las organizaciones desde el siglo pasado por autores como Ackoff (2002), Van Gich (2006), Checkland (1997), entre otros, lo cual asegurará que se consideren todas las interrelaciones entre el sistema y su ambiente y se tomen mejores decisiones al observar todas las variables y sus posibles cambios (Simancas-Trujillo, 2009). 


\section{CASO DE ESTUDIO: UNA PYME COMERCIALIZADORA}

La empresa bajo estudio se dedica al ramo ferretero y de construcción, y tiene presencia en los estados del noroeste de México (Sonora, Baja California, Baja California Sur y Chihuahua). Actualmente, se encuentra en una etapa de crecimiento, implementando a un plan de desarrollo y expansión comercial para atender los diferentes sectores industriales a los cuales van dirigidos sus productos, quienes exigen que la empresa se adapte y mejore la forma de operar para seguir ofreciendo calidad en su servicio.

No obstante, aunque es evidente el crecimiento que se refleja en un aumento en el número de puntos de venta, inversión en infraestructura y tecnología moderna, personal, mayor línea de productos y servicios, etc., con respecto a cómo inició (etapa de introducción), aún no se han establecido procesos que complemente la reestructuración física y operativa de las sucursales, sino que se opera porque "asî ha funcionado". No se tienen definidos lineamientos y estándares que respondan a un plan de gestión en el servicio a estas dimensiones, donde se permita mejorar la atención al cliente cubriendo las exigencias en el servicio del mercado actual.

Existen algunos indicadores clave que hay que atender, como un alto porcentaje de merma en el proceso de clave, así como tiempos de respuesta superiores a los permitidos, pérdidas de tiempo a causa de movimientos durante el servicio y en logística de entrega. Todos estos aspectos identificados en diferentes áreas de la organización carecen de acciones u operaciones que puedan dirigir a la organización para lograr un impacto positivo y una alineación enfocada al servicio al cliente.

Por su parte, en el área de servicios se ha detectado que la indecisión o falta de aprovechamiento de las nuevas tecnologías, hace que algunos de sus procesos no sean tan eficientes, como el reparto en el proceso de solicitud de materiales, el cual se realiza de una manera ineficiente en cuanto a tiempos y forma de elaboración.

Debido a lo anterior, se desea diseñar un sistema permita una gestión orientada a la mejora de los procesos e impactar así en la satisfacción del cliente con el servicio otorgado. Esto permitirá el cumplimiento de su estrategia competitiva de negocio, al facilitar el proceso de planeación con base en datos reales que se monitoreen a través de la medición de indicadores que indiquen el nivel la productividad del proceso. 


\section{REVISIÓN TEÓRICA}

\subsection{EL CONCEPTO DE GESTIÓN EN LOS SISTEMAS ORGANIZACIONALES}

Se entiende como un sistema organizacional a aquellos sistemas de actividad humana que se desempeñan en un entorno y utilizan otros sistemas diseñados por el hombre, para cumplir con un propósito establecido (Checkland, 1997).

Una empresa es un tipo de sistema organizacional, y se puede definir como una entidad económica cuyos integrantes persiguen múltiples intereses, comunes o no, que se reconocen como parte de un sistema mayor (la sociedad), y que solamente pueden sobrevivir cuando consideran las restricciones presentes en el contexto donde participan.

De acuerdo con el modelo de empresa de Anderton y Checkland, citado en Wilson (1993), una empresa se debe componer por diversos subsistemas, no sólo del encargado de la transformación de las entradas en las salidas esperadas por la empresa (como sus productos y/o servicios), sino que además se debe tener definido un sistema de gestión que permita que tanto en sus partes, como en el todo, se planeen, monitoreen y controlen las actividades para el logro del propósito para el cual fue establecida.

Es necesario aclarar que es común encontrar en la literatura especializada el término Gestión utilizado como sinónimo de Administración. Sin embargo, se encuentran diferencias en los conceptos, que expresan que la gestión es una actividad más compleja (ver Tabla 1), ya que no sólo busca la mejora de la productividad y la competitividad de una organización, sino que implica el diseño, implementación y control de medidas y estrategias relacionadas con todos los procesos, productivos y administrativos (Murray, 2002). 
Tabla 1. Diferencias en el concepto de gestión y administración.

\begin{tabular}{|c|c|}
\hline Gestión organizacional & \\
\hline $\begin{array}{l}\text { - Viene del latín gestio, y hace referencia a la acción y } \\
\text { consecuencia de gestionar algo. } \\
\text { - Es llevar a cabo actividades que permitan cumplir un } \\
\text { objetivo cualquiera. } \\
\text { - Hace referencia a las estrategias llevadas a cabo } \\
\text { para el logro de la misión organizacional y su viabilidad } \\
\text { económica, tomando en cuenta factores financieros, } \\
\text { productivos y logísticos. } \\
\text { - Es el proceso encargado de que las actividades se } \\
\text { desarrollen para mejorar el desempeño de todos los } \\
\text { elementos que intervienen en el sistema. }\end{array}$ & $\begin{array}{l}\text { - Viene del latín ad (hacia, dirección, tendencia) y minister } \\
\text { (subordinación u obediencia) y signifca aquel que realiza } \\
\text { una actividad bajo el mando de otro. } \\
\text { - Significa gobernar, disponer, dirigir, ordenar u organizar. } \\
\text { - Es la correcta y adecuada disposición de recursos de } \\
\text { una empresa para lograr la eficiencia en su desarrollo y } \\
\text { obtención de ganancias. } \\
\text { - Es el proceso que incluye planifcar, organizar, dirigir y } \\
\text { controlar el uso de los recursos y las actividades de trabajo } \\
\text { con el propósito de lograr las metas de la organización de } \\
\text { manera eficiente y eficaz. }\end{array}$ \\
\hline
\end{tabular}

Fuente: elaboración propia.

Una buena administración depende de una correcta gestión. La gestión puede ser vista como una herramienta que posibilita entre otras cosas generar información e integrar aquella dispersa en áreas, almacenarla y ponerla a disposición de los usuarios como bases de datos, índices, catálogos, etc., y utilizarla para tomar decisiones en un proceso de mejora continua.

\subsection{MODELOS ORGANIZACIONALES CON ENFOQUE DE PROCESOS}

Además del modelo de Anderton y Checkland citado en Wilson (1993), que indica que la empresa tiene cuatro grandes subsistemas, y que dentro de éstos se encuentran inmersas las actividades de planeación, monitoreo y control, en la literatura se reportan modelos de referencia orientados a explicitar los factores o actividades que determinan el desempeño organizacional. Se destacan los establecidos por: a) Porter (2002), que establece cinco actividades principales y cuatro de apoyo en toda empresa industrial; b) Rummler (2004), quien indica que cualquier empresa además de su cadena de valor tiene un sistema administrativo y un sistema de gestión, y c) (Arellano-González, Carballo-Mendívil, y Ríos-Vázquez, 2017), que hacen una diferencia entre los procesos de las empresas de transformación y las de servicio; y d) el modelo de sistema de gestión de calidad de ISO 9001 (2015), el cual tiene impregnado a la filosofía de mejora continua con el precepto de PlanearActuar-Verificar-Actual (PHVA).

En general, todos estos modelos indican que existen un conjunto finito de procesos como medio para entregar valor al cliente, y que de la correcta interacción entre los resultados que brindan cada una de estos procesos, dependerá el éxito de la satisfacción del cliente. 
Asimismo, existen otros modelos que detallan ciertos procesos clave que han sido diseñados con el objetivo de orientar la reingeniería y mejora de las empresas. Por ejemplo, el modelo presentado por Ramirez-Torres, Arellano-González y Carballo-Mendivil (2017), que combina el uso de las tecnologías y la mercadotecnia para generar innovación por medio del diseño conceptual de sistemas de información de mercadotecnia integral que apoyen a la pequeña empresa de servicios estudiada en la toma de decisiones y generación de ventajas competitivas.

\subsection{HERRAMIENTAS DE APOYO A LA MEJORA DE PROCESOS BAJO UN PENSAMIENTO ESBELTO}

Como lo menciona Sanz-Horcas y Gisbert-Soler (2017), el pensamiento esbelto establece un modelo de gestión basado en las personas, que define la forma de mejora y optimización en la producción bienes y servicios, focalizándose en identificar y eliminar actividades que consumen recursos y no aportan valor.

Esta filosofia de mejora ha sido aplicada exitosamente no sólo en grandes empresas, como Nike, Kimberly-Clark o Intel (Rojas-Jauregui y Gisbert-Soler, 2017), sino que también puede ser aplicada en pequeñas empresas (Sanz-Horcas y Gisbert-Soler, 2017).

Dentro de esta filosofía esbelta se ponen de manifiesto diversas herramientas y técnicas enfocadas a la creación de un flujo para poder entregar el máximo valor para los clientes, utilizando para ello los mínimos recursos necesarios (Socconini, 2008; Rojas-Jauregui y Gisbert-Soler, 2017; Sanz-Horcas y Gisbert-Soler, 2017). Algunas de estas herramientas son las siguientes:

- KAIZEN: es un sistema de mejora continua cuyos pilares son los equipos de trabajo y la Ingeniería Industrial, que se enfoca en la estandarización de procesos y la eliminación de desperdicios denominados "muda", para incrementar la productividad (AtehortuaTapias y Restrepo-Correa, 2010). Las herramientas y métodos utilizados en el kaizen son: Ciclo Planear-Hacer-Verificar-Actuar (PHVA) para la mejora continua de Deming, Justo a tiempo (JIT), Kanban, Poka yoke, Mantenimiento Productivo Total (TPM, por sus siglas en inglés), Cambios en un minuto (SMED), control visual, entre otros.

- Cinco eses (5S's): técnica utilizada para la mejora de las condiciones del trabajo de la empresa a través de una excelente organización, orden y limpieza en el puesto de trabajo (Sanz-Horcas y Gisbert-Soler, 2017). Es con la que se debe empezar a trabajar para facilitar cualquier mejora (Arrieta-Posada, 2007). Consta de cinco actividades: separar lo 
innecesario; definir un lugar para cada cosa y colocar cada cosa en su lugar; mantener la limpieza; estandarizar los procesos definiendo mecanismos de seguimiento y control; y generar una disciplina para la búsqueda de la mejora continua.

- Mapeo de la cadena de valor (Value Stream Maping, VSM): herramienta que se usa para crear mapas de flujo de información y materiales en los procesos, que promueve comenzar con un mapa de estado actual que indica la situación actual del proceso y después determinar el estado futuro del mismo al eliminar operaciones que no agregan valor, y con ello reducir el tiempo asociado, González-Torres y Velázquez-Reyes (2012).

- Hoshin Kanri: metodología que permite una sistematización de los objetivos de una organización de forma desagregada, a través del desarrollo de un sistema de gestión, implicando a distintos niveles organizacionales (Rodríguez-Balo y Ferrándiz-Santos, 2004).

\section{METODOLOGÍA}

Con el objetivo de diseñar para la empresa bajo estudio el sistema gestión orientado a la mejora de sus procesos, se tomó como referencia la metodología para el diseño de sistemas de apoyo a la gestión organizacional (MEDS), propuesta por Arellano-González, Carballo-Mendívil y RíosVázquez (2017), para establecer el siguiente procedimiento:

Paso 1. Describir la situación actual del sistema utilizando herramientas del pensamiento esbelto. Se inició haciendo una descripción detallada del proceso principal de la empresa (igualación de pinturas comercializadas), realizando un diagrama del flujo del proceso donde se identificaron las actividades clave del mismo. Se cuantificaron despilfarros de recursos identificados en él, considerando los siete tipos de desperdicios asociados a la filosofía esbelta y se mapeó en un VSM.

Paso 2. Elaborar definición raíz considerando los elementos del CATOWE. Como apoyo a la fase del diseño idealizado del sistema de gestión se elaboró una definición raíz aplicando la técnica del CATOWE, tal como lo recomiendan las metodologías de sistemas suaves (Checkland, 1997), ya que obliga a identificar a clientes, actores, actividades de transformación, responsable, propósito y ambiente donde opera el sistema.

Paso 3. Diseñar modelo conceptual idealizando el proceso en las fases del PHVA. Se diseñó el modelo conceptual del sistema de gestión idealizado para la empresa, donde se consideraron las actividades de planeación, monitoreo y control para asegurar que el proceso se autorregulara y se orientara a la mejora continua, detallando cada actividad del modelo a un segundo nivel de 
especificación. Asimismo, se elaboró el VSM del estado futuro para que se identificaran las mejoras en los indicadores del proceso rediseñado.

Paso 4. Diseñar sistemas de apoyo a la gestión a nivel estratégico y operativo que promuevan acercar la realidad de la empresa al modelo idealizado. A nivel estratégico se establecieron objetivos críticos que deben ser cumplidos, para lo cual se utilizó la herramienta Hoshin Kanri para establecer los elementos de la planeación estratégica de la compañía, así como las actividades especificas y proyectos en todos los niveles que deben desarrollarse para cumplir con sus metas, identificando objetivos críticos, restricciones, mediciones de desempeño y planes de implementación. Además, se definieron los habilitadores que se deben desarrollar en el aspecto humano para administrar el cambio y mantener las mejoras logradas con el desarrollo del proyecto.

\section{RESULTADOS}

A continuación se presentan los resultados del proyecto desarrollado en la empresa, aplicando la metodología descrita en el apartado anterior, donde el proceso estudiado es uno de los principales, ya que a través de él se desarrollan las operaciones que permiten obtener el producto a vender y generar valor al cliente.

En la Figura 1 se presenta el mapeo del flujo de valor de este proceso, que según Arellano-González, Carballo-Mendívil y Ríos-Vázquez (2017) se ubica en el centro de la cadena logística de la empresa, y es donde se genera gran parte del valor que el cliente aprecia de la empresa, ya que a través de él la empresa se asegura de la entrega del producto final. 
VSM ESTADO DEL ESTADO ACTUAL

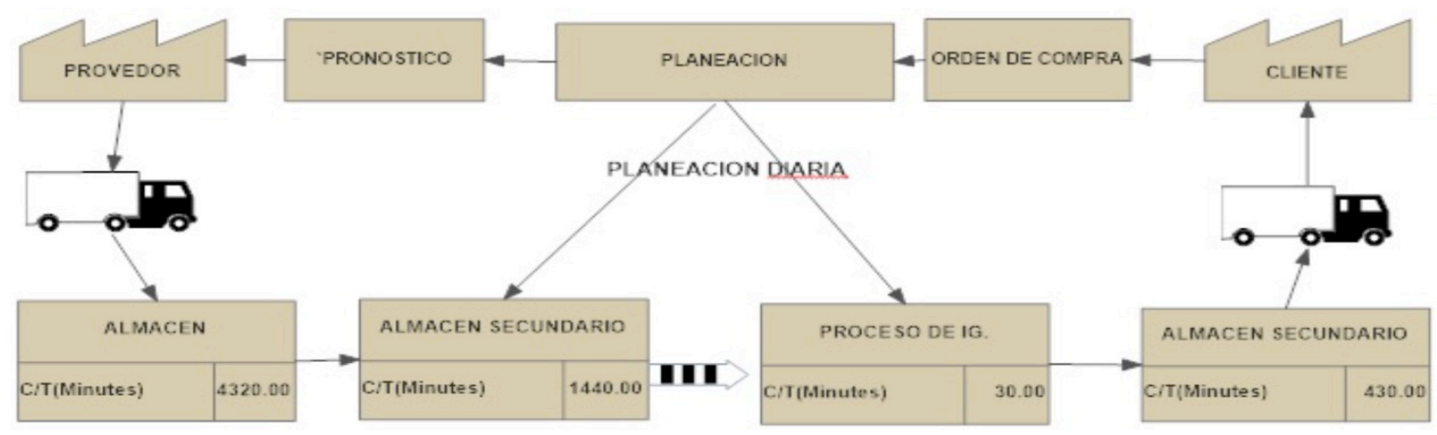

Figura 1. VSM actual del proceso bajo estudio.

Fuente: elaboración propia.

La Figura 1 se lee de derecha a izquierda a partir de la información que proporcionan las órdenes de compra de los clientes, las cuales permiten la ejecución de un proceso de planeación que emite un pronóstico de compra de material que es surtido por el proveedor. Esta actividad de abastecimiento del almacén principal actualmente toma un lapso de siete días hábiles, que en la figura se representan en minutos, y otro tiempo adicional para que el producto llegue al almacén secundario de donde puede ser tomado por el personal que procesa los pedidos del cliente y realiza las operaciones clave del proceso, para que estos puedan ser entregados al cliente que lo ha solicitado.

El análisis del proceso con esta herramienta del pensamiento esbelto permite identificar no sólo que las actividades operativas del proceso conllevan una espera que debe realizar el cliente, afectando la percepción que tiene de la empresa y su satisfacción, sino que también existen actividades administrativas y de gestión que se involucran en el logro del cumplimiento de los objetivos de la empresa vista como un todo.

Es evidente que este proceso presenta una situación problemática, por lo que se hace necesario idear un sistema de gestión que idealice el proceso clave en la generación de valor. Este ideal se declara en un solo enunciado que expresa su definición raíz como un: "Sistema de gestión para la mejora del desempeño del proceso de generación de valor, operado por el personal que atiende al cliente y su administrador, quien partiendo de un plan del desempeño, realiza planes y proyectos con base en la medición de indicadores e identificación de hechos y situaciones reales ocurridas en todos los procesos, lo cual permite la evaluación de logro de metas y objetivos, y así orientarse hacia un proceso de mejora continua que impacte directamente en la satisfacción del cliente". 
El servicio al cliente es la clave para el éxito en las empresas del sector terciario, tal como lo indica Restrepo-Ferro, Restrepo-Ferro y Estrada-Mejía (2006), quienes relacionan este éxito no sólo con el servicio al cliente, sino también con marketing, ventas, facturación y cartera. Por su parte, VarónSandoval (2013) destaca como una de las actividades clave en el servicio al cliente los elementos relacionados con áreas del conocimiento, no sólo en el marketing, sino en la calidad y la logística de las operaciones. Es por ello que las empresas deben prestar atención debida a sus sistemas de gestión y establecer esfuerzos para diseñar o rediseñar aquellos que no le permiten orientarse a la mejora.

Para mejorar la situación de la empresa, se diseñó el sistema idealizado que se presenta en el modelo conceptual de la Figura 2, el cual detalla las actividades del proceso generador de valor clasificándolas en cada una de las fases de la mejora continua: Planear $(\mathrm{P})$, Hacer $(\mathrm{H})$, Verificar $(\mathrm{V})$ y Actuar $(\mathrm{A})$.

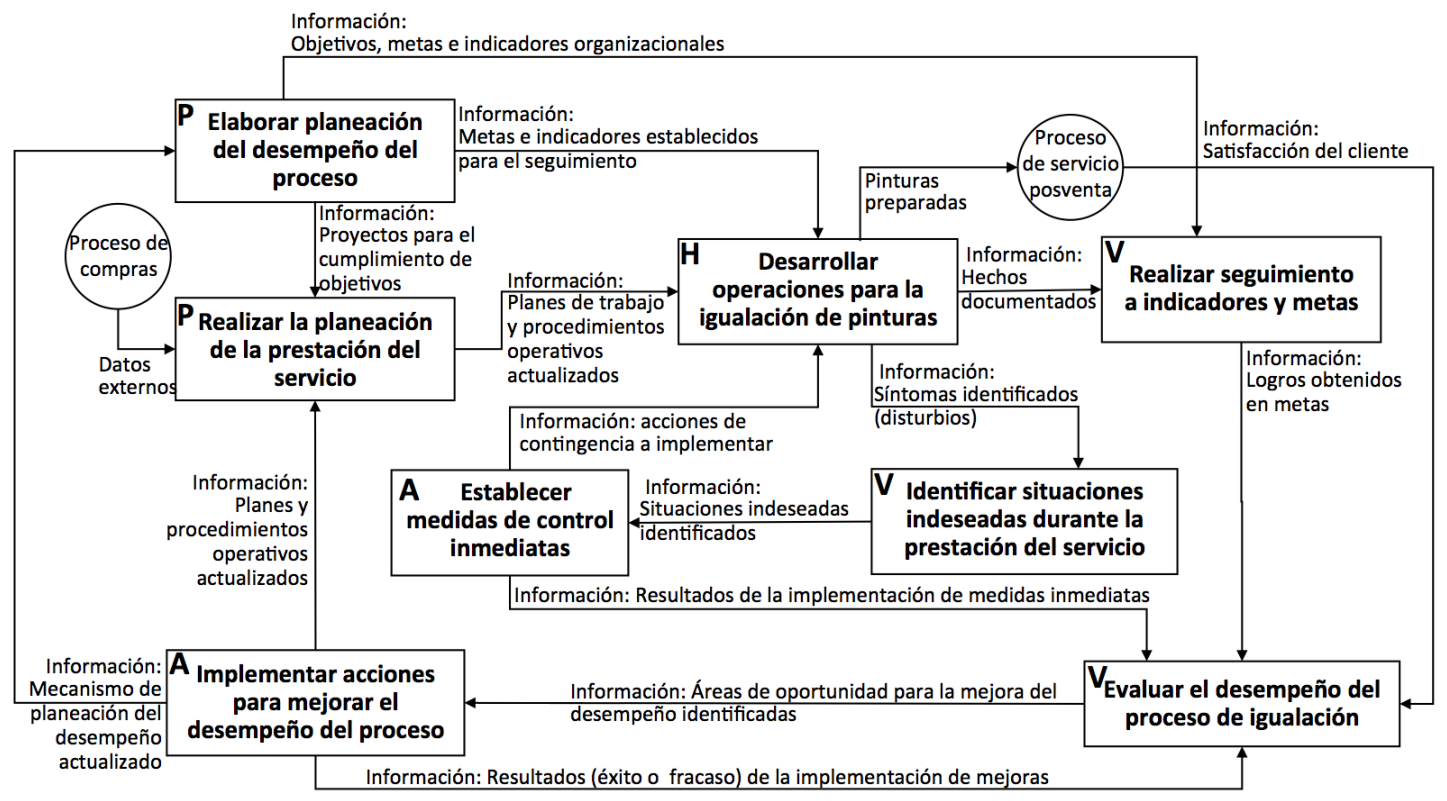

Figura 2. Modelo conceptual del sistema de operaciones para la prestación del servicio.

Fuente: elaboración propia.

El sistema de gestión idealizado en el modelo de la Figura 2 inicia con la fase del Planear al elaborar la planeación del desempeño del proceso, para lo cual se revisa la información disponible del desempeño anterior del proceso, se establecen y/o actualizan los objetivos del proceso a partir de la 
estrategia organizacional, se definen indicadores y metas, y se proponen proyectos y planes para su implementación. Una vez definido este plan, se realiza la planeación de la prestación del servicio, después de revisar los nuevos proyectos establecidos para la mejora del desempeño del proceso, establecer y/o actualizar planes de trabajo operativos, y actualizar procedimientos operativos.

Después de planear ya se puede iniciar con la fase del Hacer, donde se desarrollan las operaciones para la generación de valor en la empresa, al recibir orden de producción para el proceso, verificar datos de la orden (fecha, nombre del cliente, fecha de entrega), datos del producto (cantidad, color, base, calidad) y datos del registro (cliente, área, registro), solicitar el material requerido, realizar la preparación de igualado, de acuerdo a los requisitos de la orden de compra, así como el almacenamiento del material preparado, colocándose en el área de producto terminado, debidamente etiquetado, para su entrega, y registrar datos en el sistema de información.

Posteriormente, para cumplir con la fase del Verificar para la gestión, se deben identificar situaciones indeseadas durante la prestación del servicio, al analizar hechos ocurridos durante el desarrollo de operaciones que pongan en riesgo el logro de las metas y registrar eventos y riesgos. Con esto, se puede realizar seguimiento a indicadores y metas, al revisar información registrada sobre hechos ocurridos durante el desarrollo de actividades, calcular indicadores, determinar cumplimiento de metas y registrar los hallazgos en el sistema de información. Con toda esta información se puede evaluar el desempeño del proceso de generación de valor, al revisar información sobre logro de metas, indicadores de satisfacción al cliente y éxito de acciones de mejora implementadas y definir áreas de oportunidad para la mejora.

Por último, el sistema de gestión permite establecer medidas de control inmediata al analizar información sobre situaciones indeseadas durante el desarrollo de las operaciones, y establecer medidas inmediatas para la atención de estas situaciones indeseadas, y posteriormente implementar acciones para mejorar el desempeño del proceso al analizar área de oportunidad para la mejora definidas y establecer medidas inmediatas para la actualización de planes y procedimientos operativos, así como para los mecanismo de planeación y evaluación del desempeño.

En síntesis, el sistema de gestión que establece el modelo diseñado permite la gestión adecuada del servicio y que el proceso genere los resultados esperados, para que de esta manera no sólo se implementen cambios aislados como lo ha hecho la empresa hasta la fecha, sino que se integre con el resto de los procesos organizacionales, como el proceso de compras y de servicio posventa, manteniendo activa la relación con el cliente que demanda el producto/servicio. 
Asimismo, en la Figura 3 se presenta el mapa de flujo de valor del estado futuro en formato de VSM, donde se expresan las operaciones que se deben realizar para la generación de valor, aplicando el pensamiento esbelto, donde se indica en los círculos de los costados, aquellas actividades que no se pueden modificar, ya que son restricciones externos del sistema operativo. Sin embargo, en el círculo central sí es posible implementar mejoras para reducir los tiempos de servicio a 7 minutos por cliente, lo cual sería la meta de la fase del Hacer del sistema de gestión diseñado en la Figura 2.

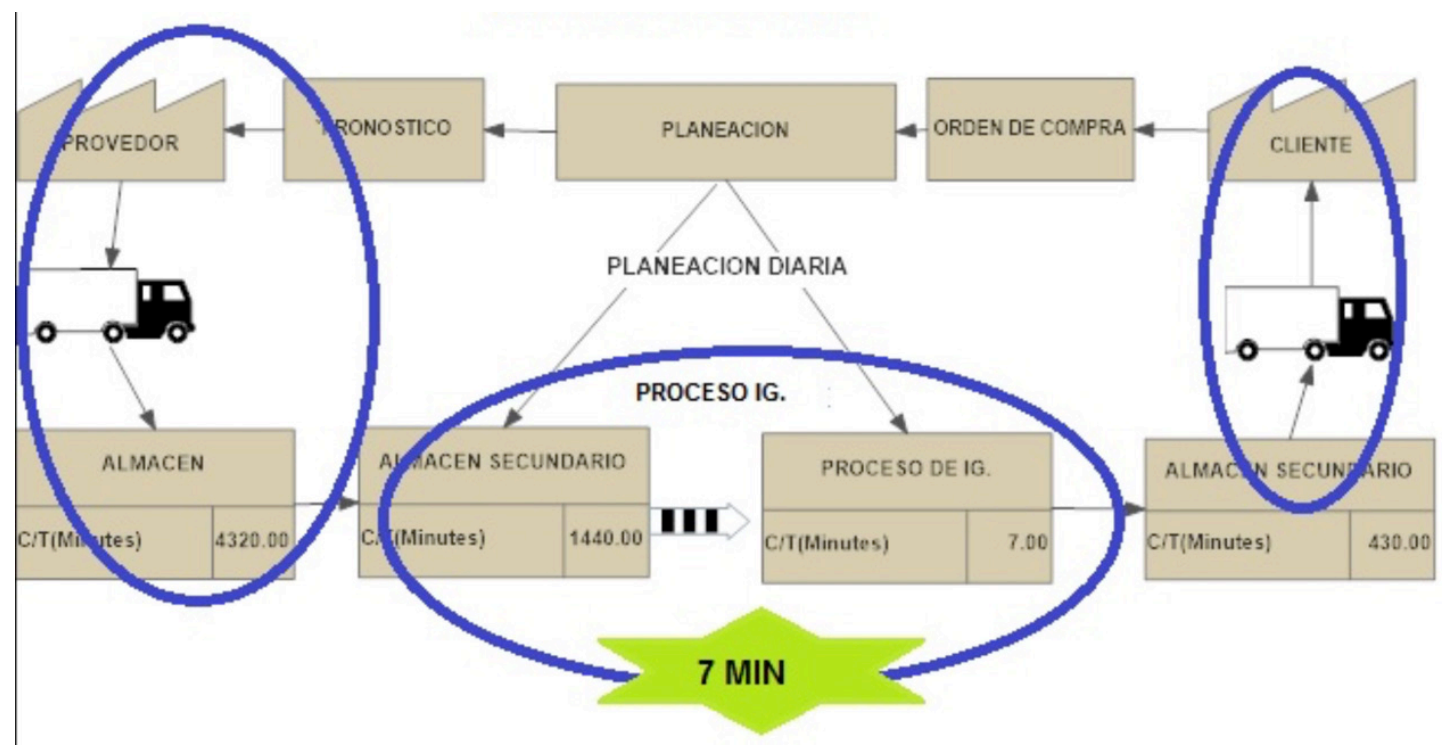

Figura 3. Mapa de flujo de valor del estado futuro del proceso bajo estudio.

Fuente: elaboración propia.

Para lograr la meta establecida en el VSM futuro de la Figura 3, se debe complementar el sistema de gestión diseñado, implementando eventos kaizen que favorezcan la mejora al definir programas operativos como la implementación de las 5S's, desarrollando a detalle los sistemas de planeación del desempeño del proceso y de la prestación del servicio, con la aplicación de herramientas como el Hoshin Kanri (ver Figura 4), y el establecimiento de indicadores y metas para la medición del cumplimiento de las directrices estratégicas, documentándolos en fichas de indicadores y box score como apoyo para el registro de los datos requeridos para el cálculo. 


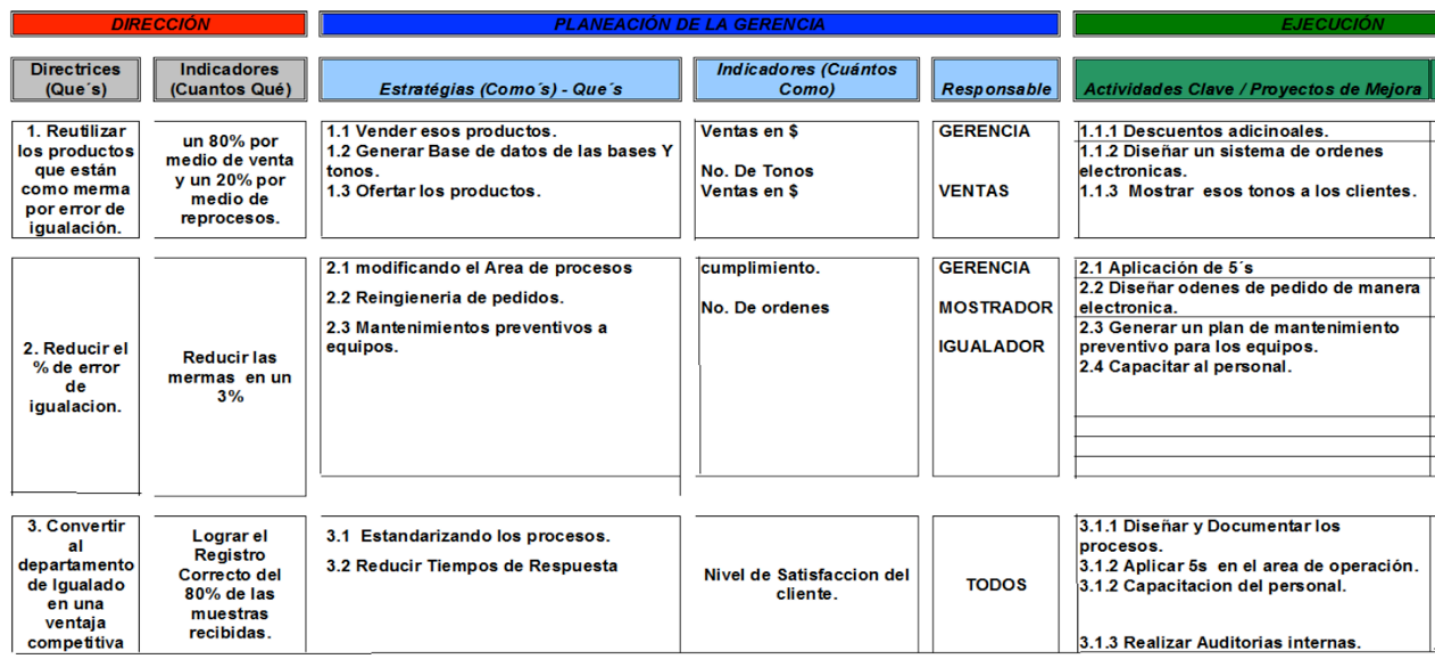

Figura 4. Plan de gestión del proceso a corto y largo plazo.

Fuente: elaboración propia.

La herramienta Hoshin Kanri permite facilitar la identificación de objetivos críticos, evaluar las restricciones, establecer mediciones de desempeño y desarrollar los planes de implementación en el sistema de gestión diseñado (Rodríguez-Balo y Ferrándiz-Santos, 2004). En la Figura 4 se pueden observar tres directrices e indicadores establecidos en el nivel directivo a través de esta herramienta, asii como las estrategias para lograrlas e indicadores para medir el avance a nivel gerencia. Asimismo, se explican las actividades a desarrollar para implementar los proyectos de mejora y sus responsables.

Por su parte, en el tablero de indicadores de la Tabla 2 se establecen las métricas que permiten realizar la planeación operativa del proceso de prestación del servicio en sus elementos estratégicos, clave y de soporte. Se entende como estratégico a aquellos que permiten la generación de datos que se requieren para determinar el nivel de logro de los resultados esperados por el proceso, mientras que los clave se relacionan con la eficiencia del proceso, y los de soporte aquellos relativos al recurso humano involucrado y el equipo utilizado. 
Tabla 2. Tabla de indicadores propuestos para la medición del sistema.

\begin{tabular}{|c|c|c|c|c|}
\hline ELEMENTO & INDICADOR & FÓRMULA & FRECUENCIA & RESPONSABLE \\
\hline \multirow[t]{3}{*}{ Estratégico } & $\begin{array}{l}\text { Impulso de productos } \\
\text { de bajo movimiento }\end{array}$ & Dato Directo & Mensual & Gerente de Ventas \\
\hline & $\begin{array}{l}\% \text { de satisfacción del } \\
\text { cliente }\end{array}$ & $\begin{array}{l}\text { \# de clientes satisfechos/ \# } \\
\text { de clientes *100 }\end{array}$ & Mensual & $\begin{array}{l}\text { Coordinador de } \\
\text { Calidad }\end{array}$ \\
\hline & $\begin{array}{l}\% \text { de crecimiento en } \\
\text { ventas }\end{array}$ & $\begin{array}{l}\text { Venta del mes en curso-Venta } \\
\text { de mes Anterior= Incremento } \\
\text { en la venta. } \\
\text { Incremento en la venta / (suma } \\
\text { de las ventas de los meses) -1 } \\
\text { *100 }\end{array}$ & Mensual & Gerente de Ventas \\
\hline \multirow[t]{3}{*}{ Clave } & Mermas de inventario & Dato Directo & Semestral & $\begin{array}{l}\text { Encargado de } \\
\text { Mostrador }\end{array}$ \\
\hline & $\begin{array}{l}\text { Índice de cancelación de } \\
\text { facturas }\end{array}$ & Dato directo & Mensual & $\begin{array}{l}\text { Encargado de } \\
\text { Mostrador }\end{array}$ \\
\hline & Nivel de servicio & $\begin{array}{l}\text { \# de órdenes de compras } \\
\text { surtidas en su totalidad/ \# de } \\
\text { ordenes. }\end{array}$ & Mensual & Gerente de Piso \\
\hline \multirow[t]{2}{*}{ Soporte } & $\begin{array}{l}\text { \% de cumplimiento } \\
\text { de las capacitaciones } \\
\text { programadas al año }\end{array}$ & $\begin{array}{l}\text { \# de capacitaciones } \\
\text { ejecutadas/ \# de } \\
\text { capacitaciones programadas } \\
\text { *100 }\end{array}$ & Semestral & $\begin{array}{l}\text { Gerente de Recursos } \\
\text { Humanos }\end{array}$ \\
\hline & $\begin{array}{l}\% \text { reducción de gastos } \\
\text { de combustible }\end{array}$ & $\begin{array}{l}\text { (Consumo de combustible } \\
\text { del mes anterior + consumo } \\
\text { de combustible del mes en } \\
\text { curso) / } 100-1\end{array}$ & $\begin{array}{l}\text { Bimestral } \\
\text { (Monitoreo) }\end{array}$ & $\begin{array}{l}\text { Encargado de } \\
\text { Flotilla Vehicular }\end{array}$ \\
\hline
\end{tabular}

Fuente: elaboración propia.

Además, el sistema de gestión requiere que los identificados que se establezcan se documenten en fichas de indicadores, como el que se representa en la Figura 5 para una de las directrices establecidas en el Hoshin Kanri, que es la reutilización de los productos considerados como merma por errores en igualación para su aprovechamiento, que para su medición se define como métrica el indicador denominado "Salida del material de merma por venta en piso", para el cual se establece una meta del $80 \%$ para efectos ilustrativos. 


\begin{tabular}{|c|c|}
\hline Ficha de indicador: & \\
\hline & \\
\hline Nombre del indicador: & Salida del material de merma $80 \%$ por venta en piso. \\
\hline Proceso: & Igualacion de pinturas. \\
\hline Objetivos: & Medir el flujo de material de merma por medio de la venta en piso. \\
\hline Alcance: & A todo el personal que labora en la organización. \\
\hline Entrada: & Inventario Inicial \\
\hline Salida: & Inventario Final \\
\hline Metodo de Obtencion: & \\
\hline 7.1 Proceso & Consultar la cantidad de unidades al inicio del proceso y al final del periodo. \\
\hline & Flujo = I inicial - I Final \\
\hline Frecuencia: & Quincenal, los dias 1ero y 15 de cada mes se evaluaran los resultados. \\
\hline Responsable: & Miriam Castañeda. \\
\hline Elaboro: & reviso: \\
\hline Puesto: & puesto: \\
\hline Fecha de elaboracion: & fecha de revision: \\
\hline
\end{tabular}

Figura 5. Ejemplo de ficha de indicadores.

Fuente: elaboración propia.

El ejemplo mostrado en la ficha del indicador de la Figura 5 representa un formato con los datos que se consideran críticos para el sistema de medición que permita evaluar el proceso y orientarlo a la mejora continua, tal como lo establece el enfoque de procesos que se promueve por la familia de normas ISO 9000 (2015).

De la misma manera, para favorecer el mantenimiento de estas mejoras, se requiere entendimiento y convencimiento de las acciones requeridas para lograr la transformación. Por ello, como apoyo se definieron una serie de habilitadores y su estrategia para desarrollar el aspecto humano (ver Tabla $3)$. 
Tabla 3. Habilitadores a desarrollar para promover el éxito en el cambio organizacional.

\begin{tabular}{|c|c|c|c|c|}
\hline Habilitadores & Planeación & Desarrollo & Implantación & $\begin{array}{l}\text { Consolidación y } \\
\text { seguimiento }\end{array}$ \\
\hline $\begin{array}{l}\text { Alineación de la } \\
\text { cultura }\end{array}$ & $\begin{array}{l}\text { Dividir por } \\
\text { segmentos y grupos } \\
\text { de empleados a la } \\
\text { organización. }\end{array}$ & $\begin{array}{c}\text { Esta etapa es relacionada } \\
\text { con la fase de } \\
\text { descongelamiento. }\end{array}$ & $\begin{array}{c}\text { Por medio de } \\
\text { reuniones, } \\
\text { capacitaciones } \\
\text { y eventos para } \\
\text { determinar hacia } \\
\text { donde se dirige la } \\
\text { empresa. }\end{array}$ & $\begin{array}{c}\text { Lograr la } \\
\text { implementación de } \\
\text { la nueva cultura } \\
\text { organizacional y } \\
\text { mantenerla en el } \\
\text { personal y personal } \\
\text { de nuevo ingreso. }\end{array}$ \\
\hline Comunicación & $\begin{array}{c}\text { Desarrollar } \\
\text { estrategia de } \\
\text { comunicación de } \\
\text { cambio. } \\
\text { Analizar las } \\
\text { herramientas de } \\
\text { comunicación para } \\
\text { la empresa }\end{array}$ & $\begin{array}{l}\text { Su objetivo es comunicar } \\
\text { y crear el canal adecuado } \\
\text { de comunicación } \\
\text { dependiendo del } \\
\text { departamento. }\end{array}$ & $\begin{array}{c}\text { Envío de } \\
\text { información de } \\
\text { interés general } \\
\text { por medios } \\
\text { electrónicos. } \\
\text { Reuniones de } \\
\text { información. }\end{array}$ & $\begin{array}{l}\text { Institucionalizar } \\
\text { el modelo de } \\
\text { comunicación interna }\end{array}$ \\
\hline Capacitación & $\begin{array}{l}\text { Necesidades } \\
\text { de capacitación } \\
\text { detectadas: } \\
\text { servicio al cliente, } \\
\text { conocimiento } \\
\text { de equipos, } \\
\text { conocimiento } \\
\text { de procesos, } \\
\text { conocimiento de } \\
\text { visión, misión } \\
\text { y valores de la } \\
\text { organización. }\end{array}$ & $\begin{array}{c}\text { El programa de } \\
\text { capacitación se divide } \\
\text { en } 3 \text { aspectos: identidad } \\
\text { (servicio al cliente, } \\
\text { misión, visión, valores); } \\
\text { procesos (conocimientos } \\
\text { de procesos) y } \\
\text { mantenimiento } \\
\text { (mantenimiento de } \\
\text { equipos.) }\end{array}$ & $\begin{array}{l}\text { De acuerdo a la } \\
\text { primera fase de } \\
\text { cambio en la cual } \\
\text { esta la organización } \\
\text { se realiza la primera } \\
\text { fase de programa } \\
\text { identidad. }\end{array}$ & $\begin{array}{l}\text { La primera fase } \\
\text { requiere de un } \\
\text { seguimiento conforme } \\
\text { se consolide la } \\
\text { identidad de la } \\
\text { organización. }\end{array}$ \\
\hline
\end{tabular}

Fuente: elaboración propia.

Estos habilitadores permitirán que lo establecido en el modelo conceptual del sistema diseñado, oriente la gestión de los procesos de la empresa bajo una filosofía de mejora continua, que aunque no es algo nuevo en la literatura, normalmente está asociada a temas de calidad como los derivados de ISO 9001. En la actualidad, las exigencias de los clientes, que han sido más evidentes desde el nuevo milenio, hacen necesario que se integren sistemas y herramientas, como se realiza en esta propuesta para la empresa bajo estudio donde se utiliza el enfoque de sistemas y el pensamiento esbelto.

Asimismo, este estudio puede ser replicado en otras pequeñas empresas como la estudiada, que no han podido formalizar sistemas de gestión ISO 9001, para ayudarlas a que generen la información 
requerida para mejorar los procesos de gestión internos, que es el primer paso que se requiere dar para poder responder a los cambios que son cada vez más rápidos y globales.

\section{CONCLUSIONES Y RECOMENDACIONES}

En la actualidad, para que una empresa sea competitiva y pueda cumplir con todos los requisitos que se le presentan, primeramente requiere contar con un sistema de gestión que le permita generar información para que pueda tomar decisiones adecuadas.

Para la empresa bajo estudio fue primordial incluir en su proceso de desarrollo, que es evidente por la expansión de sus puntos de venta, un proyecto de diseño que le garantizara establecer los procesos acordes a su plan estratégico, y que además permitiera una operación esbelta al establecer lineamientos y estándares orientados a la obtención de la calidad y la mejora del servicio al cliente, tal como lo establece esta filosofía operacional.

Lo anterior posibilitó disminuir el porcentaje de merma en el proceso de clave y el tiempo de respuesta al cliente, gracias a la implementación de mejoras a través de eventos kaizen, que permitieron reducir movimientos durante el servicio y en logística de entrega, minimizando los despilfarros detectados, logrando así un impacto positivo y una alineación enfocada al servicio al cliente, para brindarle ventajas competitivas que garanticen su permanencia en el mercado nacional, y darle las bases para competir con empresas con niveles de gestión maduros como el caso de las transnacionales.

Asimismo, la implementación del sistema de gestión de procesos propuesto para la empresa, promoverá el aprovechamiento de las tecnologías tanto para el beneficio de los procesos internos para que estos sean eficientes, como para tomar generar información que permita tomar mejores decisiones estratégicas que impacten en la competitividad de la empresa.

Sin embargo, mejorar los procesos de gestión internos es el primer paso para poder responder a los cambios que se le presentan a una empresa. Por ello, se recomienda complementar la propuesta con un sistema que permite hacer un análisis de los datos generados a través de metodologías derivados de Inteligencia Artificial, como "machine learning" o "big data", de tal manera que se puedan relacionar todos los datos que se recolecten de los procesos, clientes y del entorno, aprovechando la tecnología que actualmente disponible, y manteniéndose alerta a la forma en la que los clientes consumen, dado que estos son cada vez más cambiantes, de manera rápida y global. 


\section{AGRADECIMIENTOS}

Como parte del Laboratorio Nacional en Sistemas de Transporte y Logística-Consolidación, los autores agradecen el apoyo recibido a través del Consejo Nacional de Ciencia y Tecnología de México (CONACYT) a través del programa de "Laboratorios Nacionales". Al mismo tiempo, se agradece al Instituto Tecnológico de Sonora (ITSON) por el financiamiento otorgado a través del programa PROFAPI 2018 y PFCE 2018.

\section{REFERENCIAS BIBLIOGRÁFICAS}

Ackoff, R. L. (2002). El paradigma de Ackoff. Una administración Sistémica. México D.F., México: Limusa S.A de C.V.

Arellano-González, A., Garballo-Mendívil, B., y Ríos-Vázquez, N. J. (2017). Análisis y mejora de procesos. Una metodología con enfoque en madurez organizacional. México D.F., México: Pearson Educación.

Arrieta-Posada, J. G. (2007). Interacción y conexiones entre las técnicas 5s, SMED y Poka Yoke en procesos de mejoramiento continuo. Tecnura, 10(20), pp. 139-148.

Atehortua-Tapias, Y. A., y Restrepo-Correa, J. H. (2010). Kaizen: Un Caso De Estudio. Scientia Et Technica, XVI(45), pp. 59-64.

Gheckland, P. (1997). Pensamiento de sistemas. Práctica de sistemas. México D.F., México: Noriega.

González-Torres, A., y Velázquez-Reyes, S. M. (2012). Mapa de cadena de valor implementado en la empresa Agronopal ubicada en el D.F.. Ingeniería, 16(1), pp. 51-57.

ISO, International Organization for Standardization. (2015). Sistema de gestión de calidad - Requisitos. Ginebra, Suiza: ISO.

Murray, P. (2002). Gestión - información - conocimiento. Biblios, (14), pp. 1-11.

Pérez-Andrés, G., Gisbert-Soler, V., y Pérez-Bernabeu, E. (2017). Reingeniería de procesos. 3C Empresa, Edición Especial, pp. 81-91.

Porter, M. E. (2002). Ventaja Competitiva. Creación y Sostenimiento de un Desempeño Superior. Barcelona, España: Alay Ediciones, S.L. (Grupo patria cultural). 
Ramirez-Torres, M., Arellano-González, A., y Carballo-Mendivil, B. (2017). Modelo conceptual de gestión organizacional como referente en el desarrollo de un sistema de información de mercadotecnia integral. 3C TIC, 6(4), pp. 54-69.

Restrepo-Ferro, G., Restrepo-Ferro, L., y Estrada-Mejía, S. (2006). Enfoque estratégico de servicio al cliente. Scientia et Technica, XII, pp. 289-294.

Rodríguez-Balo, A., y Ferrándiz-Santos, J. (2004). Integración del Modelo EFQM y el despliegue Hoshin Kanri en un área de atención primaria. Revista de Calidad Asistencial, 19(1), pp. 45-52.

Rojas-Jauregui, A. P., y Gisbert-Soler, V. (2017). Lean manufacturing: herramienta para mejorar la productividad en las empresas. 3C Empresa, Edición Especial, pp. 116-124.

Rummler, G. (2004). Serious performance consulting. ISPI/ASTD.

Sanz-Horcas, J., y Gisbert-Soler, V. (2017). Lean manufacturing en pymes. 3C Empresa, Edición Especial, pp. 101-107.

Simancas-Trujillo, R. (2009). La servucción como estrategia para la recuperación del servicio no prestado en las instituciones de educación superior. Revista Colombiana de Marketing, 8(13), pp. 42-49.

Socconini, L. (2008). Lean Manufacturing. México D.F., México: Norma.

Van Gigch, J. P. (2006). Teoría general de sistemas (3ra ed.). México D.F., México: Trillas.

Varón-Sandoval, A. (2013). Constructos teóricos para abordar, de un modo investigativo, problemas entre marketing, producción y logística en las empresas colombianas. Cuadernos de Administración, 29(49), pp. 75-84.

Von Bertalanffy, L. (1968). General System Theory: Fundations, development, applications. New York, Estados Unidos: George Braziller.

Wilson, B. (1993). Sistemas: conceptos, metodologías y aplicaciones. México D.F., México: Limusa. 


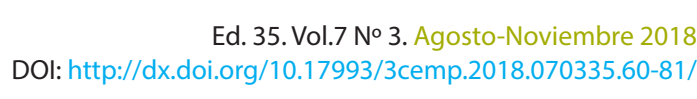

81 
/05/ 


\section{EL FRACASO DEL DINERO ELECTRÓNICO EN ECUADOR \\ THE FAILURE OF ELECTRONIC MONEY IN ECUADOR}

John Alexander Campuzano Vásquez

Coordinador del Grupo de Investigación en Desarrollo Territorial. Universidad Técnica de Machala

(Ecuador).

E-mail: jcampuzano@utmachala.edu.ec ORCID: https://orcid.org/0000-0002-3901-3197

Gonzalo Junior Ghávez Gruz

Docente. Universidad Técnica de Machala. (Ecuador).

E-mail: gchavez@utmachala.edu.ec ORCID: https://orcid.org/0000-0001-6264-8871

José Maza Iñiguez

Docente. Universidad Técnica de Machala. (Ecuador).

E-mail:jmaza@utmachala.edu.ec ORCID: https://orcid.org/0000-0001-8246-0358

Recepción: 17/03/2017. Aceptación: 01/04/2017. Publicación: 24/08/2018

Citación sugerida:

Campuzano Vásquez, J. A., Chávez Cruz, G. Jr. y Maza Iñiguez, J. (2018). El fracaso del dinero electrónico en Ecuador. 3C Empresa: Investigación y pensamiento crítico, 7(3), 82-101. DOI: http:/ / dx.doi. org/10.177993/3cemp.2018.070335.82-101/ 


\section{RESUMEN}

Este trabajo revisa la implementación del dinero electrónico en Ecuador, único caso en el mundo de administración centralizada y con economía dolarizada. Además, examina si el dinero electrónico ha logrado penetrar en la población que presenta dificultades en el acceso a los servicios financieros públicos y privados, siendo desde lo teórico el principal objetivo de su uso. La metodología que se usó es descriptiva documental, cuyo objetivo fue revisar la normativa vigente para el uso de dinero electrónico, la plataforma tecnológica usada y los agentes partícipes del proceso, sin dejar de considerar la evolución que ha tenido desde septiembre del 2014 a mayo de 2017 plazo final establecido para su uso masivo. El examen se hizo por provincias a las personas naturales y jurídicas que están realizando transacciones con dinero electrónico, los beneficios tributarios y los costos por transacción en búsqueda de una relación positiva. Se encontró que el dinero electrónico en Ecuador no ha logrado bancarizar a sectores de escasos recursos a pesar de la fuerte campaña mediática y de los beneficios tributarios entregados por el gobierno para su uso, encontrando serios cuestionamientos en los agentes privados y en los negocios para su aceptación.

\section{PALABRAS CLAVE}

Finanzas, Dinero electrónico, Beneficios tributarios, Dolarización. 


\begin{abstract}
This paper reviews the implementation of electronic money in Ecuador, a unique case in the world of centralized administration and with a dollarized economy. Also, examine if electronic money has managed to penetrate the population that presents difficulties in accessing public and private financial services, being from the theoretical the main objective of its use. The methodology used is a documentary description, whose objective was to review the current regulations for the use of electronic money, the technological platform used and the agents related to the process, without taking into account the evolution it had since September 2014. 2017 final term established for its massive use, this examination was done by provinces to individuals and legal entities that are conducting transactions with electronic money, tax benefits and transaction costs in search of a positive relationship. It was found that electronic money in Ecuador was not managed to bank in sectors of financial resources tailored to the average medical campaign and tax benefits delivered by the government for its use, finding serious questions in private agents and in business for your acceptance.
\end{abstract}

\title{
KEYWORDS
}

Finance, Electronic money, Tax benefits, Dollarization. 


\section{INTRODUCCIÓN}

Las instituciones financieras públicas y privadas juegan un papel importante dentro de la economía (Navarro y Ascencio, 2015). Éstas, incentivan el ahorro y conceden créditos de diferente tipo que activan el consumo y la inversión. En América Latina, como en otros continentes donde hay necesidades de bancarizar a las personas por su invisibilidad crediticia, la inclusión financiera es un objetivo que cobra mucha fuerza. Para ello, se crean diferentes mecanismos de apoyo que apuntan a grandes sectores productivos informales, sectores que por diversas razones no logran generar garantías ni planes financieros sostenibles por su falta de registro bancario.

Velásquez (2017) en su investigación realizada en México sobre "Avanzar en la Inclusión Financiera", señala que para reducir la pobreza en el mundo es necesario que los pobres tengan acceso global a los servicios financieros, menciona que el 89\% del crédito lo captan las grandes empresas y que solo el $11 \%$ es dirigido a las micro, pequeñas y medianas empresas (Mipymes), una realidad no muy diferente en el resto de América que contribuye a la concentración de la riqueza en grandes empresas en detrimento de las pequeñas. Con lo que el gran reto en materia de inclusión financiera no solo apunta a pequeños negocios, sino a personas y futuros emprendedores que generen empleo y mejoren sus condiciones de vida.

En esta línea argumentativa, las propuestas financieras innovadoras como el uso del dinero electrónico tienen un espacio para su aplicación, ya lo mencionan Regatto y Viteri (2017) cuando hablan de las ventajas que tienen las empresas que usan dinero electrónico, encuentran que este tipo de mecanismo genera, mayor alcance de transacciones, ventas las 24 horas, reducción de costos, y por otro lado, le da al cliente la facilidad de buscar productos en línea, ausencia de filas, entrega a domicilio y una diversificación de productos. Con lo que su uso se fortalece y lleva a pensar que es posible implementarse en nuestros países.

Iniciativas como la anteriormente mencionada, llevan en Ecuador a analizar el porqué de la propuesta de implementarlo y las decisiones de política económica que ha tomado el gobierno ecuatoriano desde el 2014, que es el año de lanzamiento de esta iniciativa para su gran empleo por medios masivos como es el uso de telefonía celular. En este sentido el Dinero Electrónico (DE, en adelante), es analizado considerando su recorrido temporal, el marco legal que lo impulsa, las decisiones económicas e incluso los procesos culturales como elementos determinantes para su éxito o fracaso, considerando que la sociedad ecuatoriana tiene ingresos medios altos, que superan algunas de las condicionantes de aplicabilidad en países que han buscado aumentar el número de transacciones bancarias en sectores pobres con dificultades de acceso a créditos productivos o de consumo. 
La investigación recoge importantes experiencias de países que vienen usando DE, y que han podido medir el impacto de su aplicación en las condiciones de vida de sus habitantes. Se toman por lo tanto, indicadores de impacto, tanto sociales, financieros, como políticos, en busca de encontrar aspectos que muestren las diferencias entre el control privado versus el público de la cantidad de circulante en un mercado de dinero como el ecuatoriano.

Además, en este trabajo se realiza una comparación y un analisis critico del DE considerando el periodo septiembre 2014 - mayo 2017, tiempo en el que se inicia la propuesta y se evidencian importantes gestiones para su difusión y uso por parte del Banco Central del Ecuador. La investigacion propone dos preguntas: ¿Por qué se da un limitado uso al dinero electrónico en este periodo? y ¿Cómo contribuir desde la academia para masificar el uso del dinero electrónico?

\section{ANTECEDENTES}

$\mathrm{Al}$ revisar la literatura en extenso se puede encontrar algunos trabajos que nos adentran al porqué del uso del dinero electrónico, es así que para Llewellyn, Vernet y Gann (2016) realizar pagos de manera móvil permite canjear dinero usando medios electrónicos a lo que describen como un sistema socio-técnico. Es un proceso que utilizando un dispositivo móvil es capaz de realizar una o varias transacciones financieras seguras con la intervención de una red móvil o inalámbricas como NFG, Bluetooth, RFID. En esta misma línea, Oliveira et al. (2016), mencionan que este nuevo sistema de pagos se diferencia por el número de actores, en la banca solo existen dos el cliente y el banco, mientras que en el pago móvil hay tres: el comprador, comerciantes y bancos. Se puede concluir que el sistema de pagos móvil admite una interacción más fuerte de personas en una cadena de comercialización de productos o servicios.

Para desarrollar un sistema de pagos moviles se necesitan dos indicadores como son la confianza y la seguridad, debido a que algunos emprendimientos de pagos electrónicos tuvieron fallas y no lograron llegar a sus destinatarios (Dahlberg, Guo, y Ondrus, 2015).

Con el tema de la seguridad están de acuerdo Oliveira et al. (2016), que al referirse al modelo de pagos por móvil, confirman que es determinante para elegir esta forma de pago por parte de los clientes, los usuarios pueden estar tranquilos que su dinero no será desviado o robado, una de las situaciones que siempre genera intranquilidad entre las personas. En el caso del Ecuador, esta percepción no ha logrado calar en los ciudadanos que siguen prefiriendo usar el dinero físico para sus transacciones, un aspecto tal vez cultural que debe ser modificado por medios comunicacionales más eficientes. 
Además de la confianza y la seguridad que deben percibir los usuarios del medio de pago móvil, autores como Venkatesh et al. (2003) adicionan cuatro constructos determinantes a la hora de admitir la nueva tecnología: rendimiento, voluntad, influencia social y la facilidad de manejo. También se pueden insertar otros indicadores como la edad, sexo y experiencia de los clientes. Coincidiendo con lo manifestado en seguridad y confianza, los que pueden ser sinónimos de rendimiento y voluntad, lo novedoso estaría en la facilidad de manejo de las instrucciones que deben ejecutarse en el dispositivo, sabiendo que el objetivo es justamente incidir en personas sin muchas posibilidades de llenar complicados formularios bancarios o manejar cajeros electrónicos sofisticados para múltiples transacciones como los que actualmente existen.

El progreso del pago móvil en países desarrollados como Japón, Corea del Sur y China, debe ser analizado respetando las diferencias propias de estas naciones, donde la existencia de plataformas tecnológicas avanzadas es superior a muchos países de África y de Latinoamérica, las que han sido diseñadas en función de los consumidores y de los bienes y servicios ofertados en los mercados. Para Miao y Jayakar (2016) la protección a los usuarios, debe considerar en la normativa del futuro las innovaciones de la Tecnología de la Información y Comunicación (TIC), así como se debe considerar que los riesgos producto de los pagos móviles deben ser asumidos el sistema financiero, para dar mayor seguridad a sus clientes

\subsection{MODELOS DE PAGO MÓVIL}

Los operadores de telefonía, la banca y otras financieras que ofrecen el servicio de pagos a terceros tienen una dura competencia por ganarse este mercado entre los que se han logrado identificar cuatro modelos:

- Modelo operador-llevado al móvil.- Aquí los gastos que ocasionan las transacciones son asumidos por las operadoras móviles. Los bancos no intervienen en ningún momento.

- Modelo operado de la propia entidad.- Los bancos realizan todas las operaciones desde su plataforma, la telefonía móvil no interviene, el banco provee el servicio y cobra a sus clientes.

- Terceras plataformas de pago dirigidos por modelos operativos.- Esta forma de pago es interesante porque el comprador primero tiene el producto para autorizar su pago, la plataforma de terceros informa al vendedor para la entrega y es independiente a los bancos, siendo muy confiable en las transacciones. 
- Modelos operativo híbridos.- Los operadores móviles se asocian con la banca, para ofrecer el servicio de pagos móviles y se asocian para tratar de dominar los mercados de pago como mencionan Ondrus y Pigneur, 2006a, 2006b, 2006c; Bossuit y Hove (2007); Zhay (2007); Zhou 2009a, 2009b; Bourreau y Vendier (2010); Mishra y Bisht (2013) citado por Miao y Jayakar, (2016).

El sistema de dinero electrónico según el gobierno ecuatoriano, busca fomentar la inclusión financiera de sectores habitualmente excluidos del sistema, a la vez, se trata de potenciar el Sistema Popular y Solidario (SPS), tal como consta en el Registro Oficial 449 de 20-oct-2008 Art. 302, 308 y 310. Las políticas monetaria, crediticia, cambiaria y financiera tendrán como objetivos: suministrar los medios de pago necesarios para que el sistema económico opere con eficiencia. Las actividades bancarias son consideradas como un servicio de orden público y podrán ejercerse, previa autorización del Estado, tendrá como finalidad la prestación sustentable, eficiente, accesible y equitativa de los servicios financieros

Art. 310.- El sector financiero público tendrá como finalidad la prestación sustentable, eficiente, accesible y equitativa de servicios financieros. También en su Art. 302.- Las políticas monetaria, crediticia, cambiaria y financiera tendrán como objetivos: suministrar los medios de pago necesarios para que el sistema económico opere con eficiencia. Y el Art. 308.- Las actividades financieras son un servicio de orden público, y podrán ejercerse, previa autorización del Estado. También mediante regulación $\mathrm{N}^{\circ}$ 0055- 2014 del $\mathrm{BCE}$, determina que el SDE es un dispositivo que permite realizar transferencia de dinero en tiempo real, mediante la utilización de las Tecnologías de Información y Comunicación (TIC).

Un aspecto relevante del DE es que es emitido por el Banco Central del Ecuador (BCE) registrándose como un pasivo que opera mediante una Plataforma de Dinero Electrónico (PDE) que es la encargada de controlar las transacciones.

El mecanismo es el siguiente: el usuario debe abrir una cuenta de dinero electrónico (CDE) que es el registro virtual y pueden ser personas naturales o jurídicas, públicas o privadas al que se le creará un usuario del Sistema de Dinero Electrónico (SDE) y éste pueda realizar transacciones a través de los monederos del sistema electrónico. El administrador de este sistema es el BCE también intervienen en el sistema el Macro Agente al sistema de dinero electrónico, que es un contrato mediante el cual se formaliza la participación de las Instituciones financiera al sistema de dinero electrónico (Registro Oficial No 208 - jueves 20 de marzo, 2014). 
Autores como Quiñonez et al. (2016) afirman, que el DE es un servicio revolucionario debido a que brinda ventajas competitivas a la población insertándolas al sistema financiero al que no ha tenido acceso, creándole la oportunidad de tener una cuenta sin la necesidad de presentarse en una institución financiera, lo que contribuye a una verdadera inclusión financiera. Entonces, no se logra entender que al ser beneficioso para el ciudadano no insertado en el sistema financiero, este no haya podido concitar la atención en la apertura de los miles de cuentas que se esperaba para el gobierno ecuatoriano, con lo que queda la duda si además de la eficiencia y eficacia del sistema, debe tomarse en cuenta la credibilidad financiera y fiscal del gobierno en ejercicio. La intencionalidad de la propuesta de DE ha sido defendida por Navarro y Ascencio, (2015) al considerar la inclusión como el objetivo a alcanzar en sectores de escasos recursos, donde la banca no ha podido entregar estos servicios y sobre todo muy cerca a el lugar de trabajo y del domicilio con bajísimos recargos y comisiones que generan un alto costo su mantenimiento.

Un trabajo de Jaime (2014) menciona que instituciones financieras con gran participación en el mercado financiero como el banco de Guayaquil y del Pichincha cuentan con un producto financiero, que lleva a la banca más cerca a sus domicilios, el sistema tiene beneficios como la reducción del papel moneda, el riesgo de robo y permite la inclusión financiera de más población. Ahora todos pueden acceder por medio de un teléfono móvil, se pueden comprar bienes y servicios, se pueden debitar y acreditar valores en tiempo real y generar mayores oportunidades a los emprendedores.

Para Bonilla et al. (2014), en Ecuador, la telefonía celular ha mejorado la inclusión financiera y que con la ayuda de la billetera móvil una propuesta del sistema, permitirá combatir la pobreza y la desigualdad en los ingresos y mejorar las condiciones de vida pues existen estudios realizados donde que existe una relación entre las variables: inclusión financiera y crecimiento económico. Por otro lado para Bonilla (2014) la banca móvil (m-banking), junto a los sistemas de pagos móviles (m-pagos) son sistemas financieros móviles que son importantes para ejecutar transacciones financieras desde cualquier lugar, con lo que las posibilidades de acceso a las personas sin bancarización, crecen de manera interesante.

Esta iniciativa de promover acceso a más personas en el sistema financiero tiene en Uruguay algo muy parecido cuando en marzo del 2014, se aprobó la ley que regula el comercio electrónico para proveedores de bienes y servicios por vía electrónica. Según el Art.2 de la Ley N ${ }^{\circ}$ 19.210, de 29 de abril de 2014, se entenderá por dinero electrónico los instrumentos representativos de un valor monetario exigible a su emisor, tales como tarjetas prepagas, billeteras electrónicas u otros instrumentos análogos, de acuerdo a lo que establezca la reglamentación, con las siguientes características: El valor monetario es almacenado en medios electrónicos, tales como un chip en 
una tarjeta, un teléfono móvil, un disco duro de una computadora o un servidor. Es aceptado como medio de pago por entidades o personas distintas del emisor y tiene efecto cancelatorio. Es emitido por un valor igual a los fondos recibidos por el emisor contra su entrega y es convertible a efectivo a solicitud del titular, según el importe monetario del instrumento de dinero electrónico emitido. Dando paso a una gran apertura, pues no se requiere de ninguna autorización ni registro previo, también es importante señalar que la factura electrónica emitida por todos los proveedores bajo este sistema sirven como sustento de costos y gastos, además se pueden señalar algunas características de la ley: es almacenado mediante un dispositivo electrónico el que puede ser activado y utilizado por un teléfono móvil, el dinero electrónico es aceptado como medio de pago, no es un depósito bancario, tampoco genera intereses y es expresado en moneda nacional (Di Martino, 2014).

La tecnología y las nuevas formas de comercio están cambiando la forma de realizar las compras, ahora es tan fácil recibir información de ofertas vía correo electrónico, así como recibir información de pagos realizados con tarjetas de crédito en tiempo real, hacer transferencias entre cuentas, etc., que casi no hay que ir a tiendas físicas, con lo que la tarjeta de crédito en poco tiempo puede ser cosa del pasado, ya que en aplicaciones puede ser guardada dentro de la memoria de teléfonos inteligentes. Algo a lo que tendremos que acostumbrarnos en mediano plazo, y para ello, es importante penetrar en el segmento de potenciales clientes que usan teléfonos celulares. En el caso del Ecuador de acuerdo a información proporcionada por la Asociación de Empresas de Telecomunicaciones (ASETEL) para el año 2018, hay 14.8 millones de líneas celulares, existiendo 4.2 millones con tecnología 4G reportando un crecimiento de 1.7 millones desde el 2016 (Diario El Universo, 2018).

En el indicador general de pagos electrónicos a nivel mundial los países de Bolivia, Ghana, India Kenya, Sri Lanka y Tanzania han logrado alcanzar la puntuación más alta que es -100- junto a la India, siendo países que han logrado una masiva utilizacion debido a que tienen una poblacion que no está en su mayoría insertada a servicios bancarios, a lo que se le añade que estos paises no tienen buena comunicación, la capacidad de compra es muy baja. Vale indicar que el indicador se calcula con la base de datos Global Findex Del Banco Mundial el mismo que consiste en el: uso de la telefonía móvil para recibir dinero (\% mayores de 15 años) (Economist Intelegent Unit, 2016). Es importante analizar el caso de Bolivia y que aparece como uno de los mejores puntuados en la inclusión financiera de sus ciudadanos al tener una población mayoritaria de indígenas que no logran insertarse al sistema financiero tradicional. 


\subsection{REGULACIÓN DINERO ELECTRONICO EN ECUADOR}

Tabla 1. Montos de las transferencias con DE.

\begin{tabular}{|c|c|c|c|}
\hline \multirow{2}{*}{\multicolumn{2}{|c|}{ Usuario }} & \multicolumn{2}{|c|}{ Monto Mensual } \\
\hline & & \multirow{2}{*}{$\begin{array}{l}\text { Máximo } \\
0,00\end{array}$} & \multirow[b]{2}{*}{$9.000,00$} \\
\hline Persona natural & & & \\
\hline \multirow{5}{*}{$\begin{array}{l}\text { Persona jurídica o } \\
\text { natural obligada a llevar } \\
\text { contabilidad }\end{array}$} & Segmento 5 & 0,00 & $20.000,00$ \\
\hline & Segmento 4 & 0,00 & $100.000,00$ \\
\hline & Segmento 3 & 0,00 & $500.000,00$ \\
\hline & Segmento 2 & 0,00 & $1.000 .000,00$ \\
\hline & Segmento 1 & 0,00 & ilimitado \\
\hline Macroagente & & 0,00 & ilimitado \\
\hline Administrador del SDE & & 0,00 & ilimitado \\
\hline
\end{tabular}

Fuente: Banco Central, 2014.

El dinero electrónico es un medio de pago gestionado por el Banco Central y se instrumenta a través del Art.1. Res. 005-2014-M, Junta de Regulación Monetaria y financiera:

- Sistema de Dinero Electrónico (SDE)

- Plataforma de dinero electronico (PDE)

- Manual de procedimiento y operación del sistema de dinero electronico (MPO)

- Reglamento de participantes del SDE (RPDE)

- Cuenta de dinero electronico (CDE)

- Monedero electronico (MOE)

- Acuerdo de Conexión (ACO)

- Operadores tegnologicos de telecomunicaciones

- Participantes

- Administrador del SDE

- Macroagentes

- Centro de transacción

- Usuarios 
Entidades reguladora: Junta de Política y Reguladora Monetaria y Financiera

- Consejo Nacional de Telecomunicaciones (CONATEL)

- Secretaria Nacional de Telecomunicaciones (SENATEL)

- Superintendencia de Telecomunicaciones (SUPERTEL)

- Superintendencia de Bancos

- Superintendencia de Compañías Valores y Seguro

- Superintendencia de Compañía Popular y Solidaria

- Superintendencia de Control del Poder de Mercado

Art.2. Casos de uso del DE

\subsection{ACTIVACION DE UNA CUENTA DE DINERO ELECTRÓNICO CDE}

Una persona naural o juridica para activar una CDE deberá registrar sus datos en el SDE realizando los siguientes pasos en la web del SDE.

- Marca*153\#, aparece la elección SÍ o NO

- Acepta los términos y condisiones

- Registrase como persona natural o jurídica

- Ingresa tu número de cédula o RUC

- Nombres y apellidos, razón social de la empresa

- Deberás responder a las afirmaciones

- Cambiar la clave temporal marcando*153\#

Carga de dinero electrónico

El usuario que tenga una CDE, podra cargar a su monedero dólares en un centro de transaccion

Siguiendo los siguientes pasos:

- Valor a cargar mas cédula de identidad

- Al macroagente entregar el dinero fisico

- Llegara un mensaje de texto al teléfono para confirmar la operación 
Descarga de Dinero Electrónico

El ususario de DE podra retirar dólares desde su monedero en cualquiera de los centros de transaccion autorizados por el BCE.

Giro

Una persona natural o jurídica podrá desde su CDE enviar dinero a una persona natural que no dispone de esta cuenta

Transferencia

El usuario de CDE podrá trasferir dólares a cuentas del mismo usuario en el sistema financiero nacional.

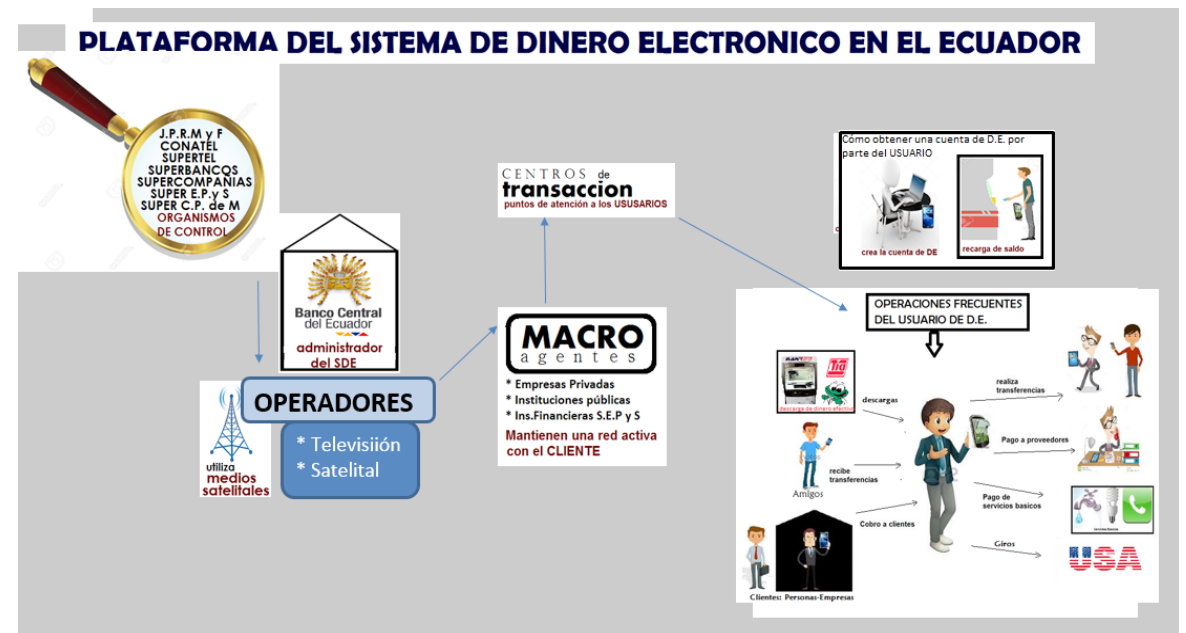

Figura 1. Actores principales del SDE y su control.

Fuente: Banco Central del Ecuador elaborado por los autores.

Primero se debe abrir una cuenta DE digitando *153\# desde su celular, luego se ingresa el numero celular al que se quiere pagar, se ingresa el valor del pago, se digita la clave para autorizar el pago, el beneficiario recibe un mensaje desde la plataforma y el beneficiario recibe un mensaje de texto de confirmación de pago. Para cargar y descargar DE, el usuario deberá acercarse a un centro de transacciones autorizadas que puede ser Institución financiera pública o privada, Sistema de Economía Popular y Solidaria, entidad Pública o Entidad Privada. 


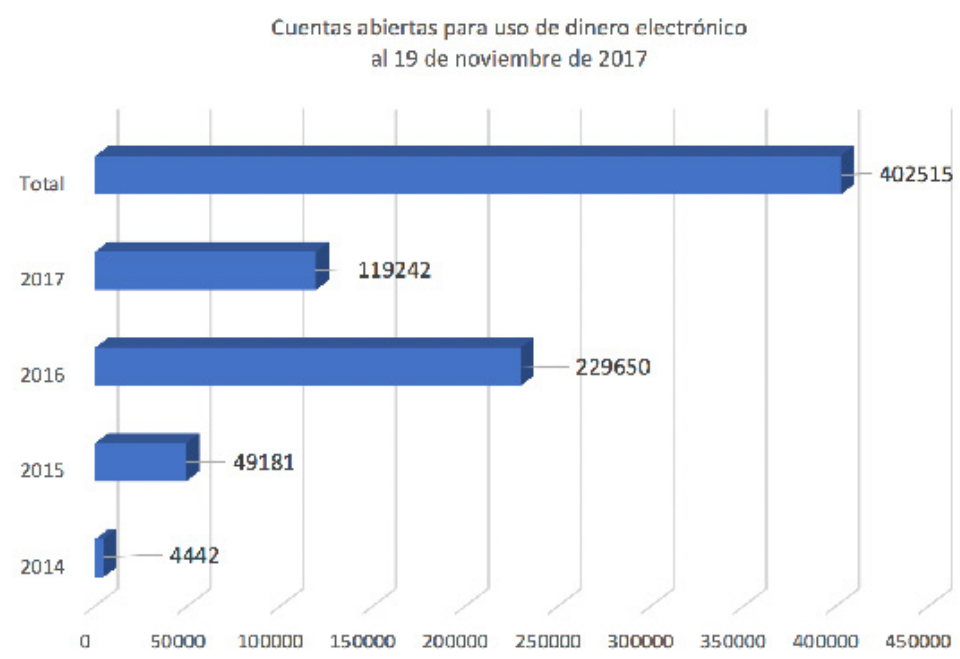

Figura 2. Evolución de las cuentas abiertas de DE.

Fuente: Banco Central del Ecuador 2017 elaborado por los autores.

Se puede observar que desde la creación de la iniciativa, el DE no concitó el interés de los potenciales usuarios, para algunos analistas económicos, producto del divorcio de la propuesta con los miembros del sistema financiero, ya que la exclusividad de la operación recayó en el BCE el que obligaba a los Bancos y Cooperativas a ser parte sin tener mayor incentivo en su rentabilidad. Para corregir el desinterés de los ciudadanos, se puso en vigencia el Decreto Ejecutivo 1064, Registro Oficial 771 de 8 de junio del 2016, que permite la devolución del IVA con lo que se observa un crecimiento algo importante llegando a 229.650 cuentas abiertas de 49.181 del año anterior un 467 por ciento aproximadamente. 
Personas naturales y juridicas que cobran en efectivo desde el celular por provincias. Corte 12-03-2017

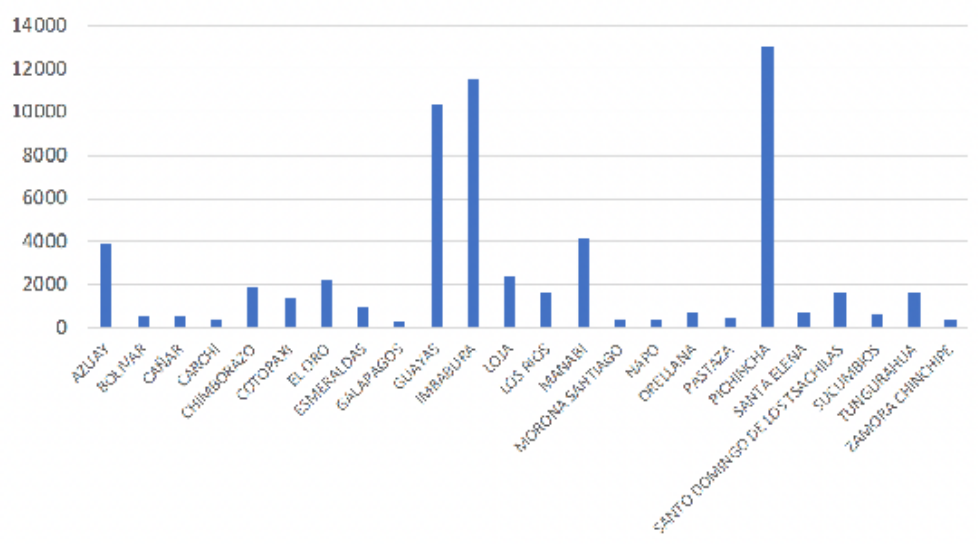

Figura 3. Personas naturales y jurídicas que cobran en efectivo desde el celular. Corte 12-03-2017. Fuente: Servicio de Rentas Internas 2017 elaborado por los autores.

El DE en Ecuador analizado por provincias es mayormente utilizado en la provincia de Pichincha con 12.972 personas, seguido de Imbabura con 11.564 y, en tercer lugar la provincia de Guayas con 10.374 personas. El resto de provincias tienen una participación insignificante dentro del país, la explicación es que estas provincias concentran mucho dinamismo económico y los almacenes más grandes se han adherido a la iniciativa de cobro de servicios y productos vía dinero electrónico. Las personas en estas provincias están más informadas de los beneficios de la devolución de 2 puntos del impuesto al Valor Agregado (IVA) al utilizar DE, hay que señalar que solo en el año 2017 se realizaron transacciones por 45,046,455 millones de dólares según el BCE cifra distante del objetivo inicial.

Además, se cuenta con el Anticipo del Impuesto a la Renta (AIR) permitiendo que todos los costos y gastos realizados por personas y empresas con DE, sean excluidos para el cálculo y pago del AIR. Los contribuyentes del Régimen Impositivo Simplificado (RISE) que son los pequeños comerciantes, tienen derecho a la devolución del 5\% sin intereses por el pago puntual de este tributo, tambien el $5 \%$ por las compras y ventas realizadas con DE. 
Tabla 2.Tarifas por utilización de DE.

\begin{tabular}{|c|c|c|c|}
\hline Cobro de Comisión por Servicios del BC & $\begin{array}{c}\text { Costo } D E \\
\text { transacción }\end{array}$ & $\begin{array}{l}\text { Monto } \\
\text { Mínimo }\end{array}$ & Monto Máximo \\
\hline Activación de cuenta DE & 0.00 & 0.00 & 0.00 \\
\hline $\begin{array}{l}\text { Depósito y recarga DE en un centro de transacción a una } \\
\text { CDE persona natural } \\
\text { Servicio de Cajero Persona Natural } \\
\text { Servicio de Cajero Persona Jurídica }\end{array}$ & $\begin{array}{l}0.00 \\
0.10 \\
0.15\end{array}$ & $\begin{array}{l}1.00 \\
5.00 \\
5.00\end{array}$ & $\begin{array}{l}500.00 \\
500.00\end{array}$ \\
\hline Mantenimiento de cuenta DE & 0.50 & & \\
\hline $\begin{array}{l}\text { Giro nacional } \\
\text { Recepción de un giro exterior a una CDE }\end{array}$ & $\begin{array}{l}0.50 \\
0.35\end{array}$ & $\begin{array}{l}10.00 \\
0.10\end{array}$ & $\begin{array}{l}300.00 \\
5,000.00\end{array}$ \\
\hline Consultas de saldos en la cuenta DE & 0.05 & & \\
\hline Certificación DE & 0.5 & 1 & En adelante \\
\hline Retiro de DE desde la cuenta & 0.15 & & \\
\hline Transacción en consumo nacional DE & 0.05 & & \\
\hline
\end{tabular}

Fuente: Junta de Regulación Monetaria Financiera Res. № 252-2016-M del 14/06/2016.

Elaboración: autores.

La evidencia en Ecuador desde su creación y sustento en el Código Orgánico Monetario y Financiero del año 2014, indica que la mayoría de las transacciones que realizan los ecuatorianos sigue sustentada en el efectivo, con mucha preferencia en el sector rural y el urbano marginal de las grandes ciudades y provincias. No ha servido entonces los argumentos esgrimidos desde la esfera gubernamental que proteger la dolarización necesita de este tipo de medios para favorecer las transacciones económicas, comerciales y financieras, afirmando que ayuda al país en la reducción de costos por reposición del dinero físico.

\section{CONCLUSIONES}

El DE es manejado y administrado por el estado ecuatoriano a través del BCE asociado con los bancos y cooperativas del sistema financiero, donde los usuarios pueden realizar transacciones y recargas abriendo una CDE con la cual podrá: realizar transferencias a otras cuentas, pagar a proveedores, servicios básicos, impuestos y realizar giros a otros países.

Desde el punto de vista de lo social, el dinero electrónico desde su creación no ha logrado el objetivo inicial de la inclusión financiera en los ecuatorianos con bajos ingresos, con lo que no se ha 
conseguido generar nuevos emprendimientos a través del crédito para actividades productivas y de expansión. Tampoco se tienen estadísticas asociadas a la reducción de la evasión fiscal, producto de la formalización financiera de miles de ecuatorianos vía DE, ya que la cantidad de cuentas nuevas no llega a los mínimos esperados desde su creación.

Las comisiones vigentes por el BC son realmente mínimas con respecto a la banca privada, sin embargo, no se ha conseguido motivar a los ciudadanos, los mismos que continúan accediendo al sistema financiero formal y a los agiotistas de la economía informal. La campaña masiva de información que ha desarrollado el gobierno nacional en medios de comunicación públicos no ha contado con el respaldo de los instituciones del sistema de educación superior para capacitar a los agentes económicos y beneficiarios sobre las bondades del uso, a fin de reducir costos en el sistema de dolarización que funciona en Ecuador desde el año 2000, se han enfocado al público general sin tener el impacto positivo que se pueda medir en cifras positivas tanto en número y monto de transacciones, como de nuevas cuentas creadas. 


\section{REFERENCIAS BIBLIOGRÁFICAS}

Bonilla, C. E. (2014). Análisis de iniciativa estatal para la reducción de la pobreza en Ecuador: caso "Billetera Móvil" de Banco Central del Ecuador. Guayaquil, Ecuador. Recuperado el 10 de 05 de 2017, de: http:/ /www.dspace.espol.edu.ec/xmlui/handle/123456789/30615

Bonilla, G., Zanzzi, P., y Vera, G. (2014). La "Billetera Móvil" del BCE, una iniciativa estatal contra la pobreza: efectos económicos. Ciencia UNEMI, 8(13), pp. 100-111. Recuperado el 11 de 05 de 2017, de: https:// dialnet.unirioja.es/servlet/articulo?codigo=5187843

Dahlberg, T., Guo, J., y Ondrus, J. (2015). A critical review of mobile payment research. Electronic Commerce Research and Applications, 19. Recuperado el 18 de 05 de 2017, de: www.elsevier.com/ locate/ ecra

Di Martino, E. M. (2014). Comercio electronico en Paraguay: alcanzando metas. FAIIO-SID, 15. Recuperado el 13 de 05 de 2017, de: http://sedici.unlp.edu.ar/bitstream/handle/10915/42110/ Documento_completo.pdf? sequence $=1$

Diario El Universo. (2018). Líneas celulares llegan a 14.8 millones en 2018. El Universo, p. 5.

Economist Intelegent Unit. (2016). Microscopio Global 2016: análisis del entorno para la inclusión financiera. New York: Fundación metlife.org. Recuperado el 27 de 05 de 2018, de: https:/ / publications. iadb.org/bitstream/handle/11319/7988/Microscopio-global-2016-Analisis-del-entorno-para-lainclusion-financiera.pdf?sequence $=2$ yisAllowed $=\mathrm{y}$

Jaime, E. E. (2014). El Dinero Electrónico en el Ecuador. Res Non Verba, 4(2). Recuperado el 11 de 05 de 2017, de: http://biblio.ecotec.edu.ec/revista/articulo.php?id=27 1

Llewellyn, D. T., Vernet, A., y Gann, D. M. (2016). Preparación para la adopción de la innovación de servicios: el caso del dinero digital. Industru and Innovation, 23(4), pp. 353-381. Recuperado el 01 de 07 de 2017.

Miao, M., y Jayakar, K. (2016). Mobile payments in Japan, South Korea and China: Cross-border convergence or divergence of business models? Telecommunications Policy, 40(2-3), pp.182-196. doi: https://doi.org/10.1016/j.telpol.2015.11.011 
Navarro Espinoza, J. A., y Ascencio Jordán, E. d. (2015). Impacto Económico de la Implementación del Sistema de Dinero Electrónico en el Ecuador. Obsevatorio Economiía Latinoamericana, 7. Recuperado el 10 de 07 de 2017, de: http://www.eumed.net/cursecon/ecolat/ec/2015/dineroelectronico.html

Oliveira, T., Thomas, M., Baptista , G., y Campos, F. (2016). Mobile payment: Understanding the determinants of customer adoption and intention to recommend the technology. Computers in Human Behavior, 61, pp. 404-414. doi:https://doi.org/10.1016/j.chb.2016.03.030

Quiñonez Alvarado, E., Durán Salazar, G., Vera Franco, P., y Brito Ochoa , M. (2016). El dinero electrónico como medio de pago para la inclusión financiera en Ecuador. INNOVA, 11. Recuperado el 10 de 05 de 2017, de: http://www.journaluidegye.com/magazine/index.php/ innova/article/view/38

Regatto Bonifaz, J. D., y Viteri Miranda, V. M. (2017). El comercio electrónico como ventaja competitiva. Recuperado el 09 de 05 de 2017, de: http://www.eumed.net/libros-gratis/actas/2017/ empresas/28-el-comercio-electronico.pdf

Registro Oficial No 208 - 20 de Marzo. (2014). Dinero Electrónico. Quito, Ecuador: Registro Oficial. Recuperado el 10 de 05 de 2017, de: https://www.registroficial.gob.ec/index.php/registrooficial-web/publicaciones/registro-oficial/item/21 18-registro-oficial-no-208.html

Venkatesh, V., Morris , M. G., Davis, G. B., y Davis, F. D. (2003). User Acceptance of information technology: Toward a Unified View. Mis Quarterly, 27(3), pp. 425-478. Recuperado de: https://www.jstor.org/stable/30036540 


\section{Consejo Editorial}

$\begin{array}{ll}\text { Director } & \text { Víctor Gisbert Soler } \\ \text { Editores adjuntos } & \text { María J. Vilaplana Aparicio } \\ & \text { Inés Poveda Pastor } \\ & \text { Vicente Sánchis Rico } \\ \text { Editores asociados } & \begin{array}{l}\text { David Juárez Varón } \\ \text { F. Javier Cárcel Carrasco }\end{array}\end{array}$




\section{Comité Científico Técnico}

Área textil

Área financiera

Organización de empresas y RRHH

Estadística; investigación operativa

Derecho

Ingeniería y tecnología

Tec. de la información y la comunicación

Medicina y salud
Prof. Dr. Josep Valldeperas Morell

Universidad Politécnica de Cataluña, España

Prof. Dr. Juan Ángel Lafuente Luengo

Universidad Faume I; Castellón de la Plana, España

Prof. Dr. Francisco Llopis Vañó

Universidad de Alicante, España

Prof. Dra. Elena Pérez Bernabéu

Universidad Politécnica de Valencia, España

Prof. Dra. María del Carmen Pastor Sempere

Universidad de Alicante, España

Prof. Dr. David Juárez Varón

Universidad Politécnica de Valencia, España

Prof. Dr. Manuel Llorca Alcón

Universidad Politécnica de Valencia, España

Dra. Mar Arlandis Domingo

Hospital de San Juan de Alicante, España 

3c) empresa 